\title{
Development of a Solid-Phase Extraction (SPE) Cartridge Based on Chitosan-Metal Oxide Nanoparticles (Ch-MO NPs) for Extraction of Pesticides from Water and Determination by HPLC
}

\author{
Mohamed E. I. Badawy (D), Mahmoud A. M. El-Nouby, and Abd El-Salam M. Marei \\ Department of Pesticide Chemistry and Technology, Faculty of Agriculture, Alexandria University, El-Shatby, Alexandria 21545, Egypt
}

Correspondence should be addressed to Mohamed E. I. Badawy; m_eltaher@yahoo.com

Received 17 March 2018; Revised 31 July 2018; Accepted 2 September 2018; Published 2 October 2018

Academic Editor: Valentina Venuti

Copyright @ 2018 Mohamed E. I. Badawy et al. This is an open access article distributed under the Creative Commons Attribution License, which permits unrestricted use, distribution, and reproduction in any medium, provided the original work is properly cited.

\begin{abstract}
The present study aims to prepare two new types of chitosan-metal oxide nanoparticles (Ch-MO NPs), namely, chitosan-copper oxide nanoparticles (Ch-CuO NPs) and chitosan-zinc oxide nanoparticles (Ch-ZnO NPs), using sol-gel precipitation mechanism, and test them new as adsorbent materials for extraction and clean-up of different pesticides from water. The design of coreshell was implemented by metal oxide core with chitosan as a hard shell after crosslinking mechanism by glutaraldehyde and then epichlorohydrin. The characterizations of the prepared nanoparticles were investigated using Fourier transform infrared spectrometry (FT-IR), zeta potential, scanning electron microscopy (SEM), transmission electron microscope (TEM), and X-ray diffraction (XRD). FT-IR confirmed the interaction between chitosan, metal oxide, and crosslinking mechanism. SEM and TEM explained that the nanoparticles have a spherical morphology and nanosize of 93.74 and $97.95 \mathrm{~nm}$ for $\mathrm{Ch}-\mathrm{CuO} \mathrm{NPs}$ and $\mathrm{Ch}-\mathrm{ZnO}$ NPs, respectively. Factorial experimental design was applied to study the effect of $\mathrm{pH}$, concentration of pesticide, agitation time, and temperature on the efficiency of adsorption of pesticides from water samples. The results indicated that optimum conditions were $\mathrm{pH}$ of 7 , temperature of $25^{\circ} \mathrm{C}$, and agitation time of $25 \mathrm{~min}$. The SPE cartridges were then packed with Ch-MO NPs, and seven pesticides of abamectin, diazinon, fenamiphos, imidacloprid, lambda-cyhalothrin, methomyl, and thiophanate-methyl were extracted from water samples and determined by HPLC. The extraction efficiency of Ch-ZnO NPs was higher than Ch-CuO NPs, but both removed a larger amount of most of tested pesticides than the standard ODS cartridge (C18). The results showed that this method achieves rapid and simple extraction in small quantities of adsorbents (Ch-MO NPs) and solvents. In addition, the method is highly sensitive to pesticides and has a high recovery rate.
\end{abstract}

\section{Introduction}

Pesticides are widely used in agricultural production to prevent or control pests, diseases, weeds, and other plant pathogens in an effort to minimize or eliminate yield losses and maintain high quality of products $[1,2]$. Widespread uses of pesticides with all groups such as organochlorines, organophosphorus, carbamates, pyrethroids, and neonicotinoids have resulted in extensive contamination of water, atmosphere, and soil as well as agricultural products which eventually lead to food safety issues [3]. Water contamination with pesticides is considered a serious problem and may pose a risk to human health such as acute neurological toxicity, neurodevelopmental impairment, cancer, allergies, neurological disorders, and reproductive disorders $[2,4-6]$.

Different analytical techniques have been used for sample preparation and clean-up with differentiation of sensitivity and selectivity [7], which include liquid-liquid extraction (LLE) [8], solid-phase extraction (SPE) [9], solid-phase microextraction (SPME) [10], dispersible solid-phase extraction (d-SPE), headspace solid-phase extraction [11], and stir bar sorptive extraction (SBSE) [12]. SPE was introduced in the early 1970s to avoid and minimize the disadvantage of LLE technique. The SPE is a superior extraction and clean-up 
method that uses a solid phase and a liquid phase to separate the analyte from the sample without impurities before analysis by dint of speed, less usage of organic solvent, low cost, and ability to obtain a higher preconcentration factor $[13,14]$. Recently, advanced materials for SPE extraction have been investigated with separation by liquid chromatography and ultraviolet absorption detection (HPLC/UV) [15-17].

Some of the most common sorbents in SPE are generally similar to those in column liquid chromatography such as the primary secondary amine (PSA), octadecyl-siloxane $\left(\mathrm{C}_{18}\right)$, graphitized carbon black (GCB), alumina, and florisil. PSA is normally used in the d-SPE to remove interferences, such as free fatty acids, sugars, and other nonpolar compounds from the sample. However, the most commercial stationary phase used in SPE is octadecyl-siloxane $\left(\mathrm{C}_{18}\right)$ used in the reversed phase to extract the nonpolar compounds like pesticides $[18,19]$.

Recently, the biopolymer materials have been shown to be of low cost and good efficiency in removal of various contaminants from aqueous media. Among these biopolymers, chitosan (poly- $\beta$-(1 $\longrightarrow 4$ )-2-amino-2-deoxy-D-glucose) [20, 21] has been considered to be one of the most promising and applicable materials in adsorption applications [22]. The existence of the two functional groups of hydroxyl $(-\mathrm{OH})$ and amino $\left(-\mathrm{NH}_{2}\right)$ in its molecular structure contributes to many possible adsorptions and gives highly powerful removal capacity of dyes, metal ions, phenols, pharmaceuticals drugs, and other pollutants including the pesticides from environment and wastewater [23].

Metal oxide particles have been used in many functions [24] in various polymeric materials to improve the permanence of the polymeric products [25]. In addition, the nanoparticles of these products could increase the stiffness, toughness, and service life of polymeric materials [26]. The chitosan-metal oxide complexes in nanostructure form have been extensively modified to improve the adsorption capacity of chitosan molecule because of their limited size and a high density in their corner or edge surface sites [6]. Dehaghi and coauthors synthesized the chitosan- $\mathrm{ZnO}$ nanoparticles (Ch-ZnO NPs) for adsorption applications in the removal of pesticide pollutants [25]. They found that the $0.5 \mathrm{~g}$ of the $\mathrm{Ch}-\mathrm{ZnO} \mathrm{NPs}$, in room temperature and $\mathrm{pH} 7$, removed $99 \%$ of permethrin insecticide solution $(0.1 \mathrm{mg} / \mathrm{L})$. Copper-coated chitosan nanocomposite ( $\mathrm{Ch}-\mathrm{Cu}$ ) was prepared and used for adsorption of parathion and methyl parathion insecticide in the batch mode. The maximum adsorption capacity of malathion was found to be $322.6 \mathrm{mg} / \mathrm{g}$ at an optimum $\mathrm{pH}$ of 2.0. The adsorbent was found to remove malathion completely from the spiked concentration of $2 \mathrm{mg} / \mathrm{L}$ in one min in the agricultural run-off samples [24].

Chemical modification promotes crosslinking of the polymer chains. This process consists of joining polymer chains with the help of high reactivity chemicals called crosslinking agents, generating polymer networks. This modification type is only possible by the presence of functional groups of high reactivity in the structure of these polymers. Most notably, glutaraldehyde and epichlorohydrin as crosslinking agents considerably improve the mechanical strength, the hardness of the chitosan particles, and the chemical stability in acidic media [27, 28]. Epichlorohydrin was selected as a convenient base catalyzed crosslinking agent. An advantage of epichlorohydrin is that it does not eliminate the cationic amine function of chitosan, but it reacts with hydroxyl groups in chitosan. Glutaraldehyde has been used more frequently since it is less expensive, nontoxic, and highly soluble in aqueous solution. It is a dialdehyde whose aldehydic groups are highly reactive and can form covalent bonds with functional groups such as primary amine by Schiff base suggesting that the conjugated aldehyde moieties in the polymers yield more stable reaction products [29-31].

In the current study, new chitosan-metal oxide nanoparticles (Ch-MO NPs) including chitosan-CuO nanoparticles (Ch-CuO NPs) and chitosan- $\mathrm{ZnO}$ nanoparticles (Ch-ZnO NPs) were prepared through the crosslinking mechanism by glutaraldehyde and then epichlorohydrin. The nanoparticles were used as a stationary phase in the preparation of SPE cartridge. The SPE cartridges were used in extraction and cleanup of pesticides from water samples. The efficiency of the prepared cartridge of adsorption or retention of the different pesticides including abamectin, diazinon, fenamiphos, imidacloprid, lambda-cyhalothrin, methomyl, and thiophanate methyl was tested at three concentrations of each pesticide. The targeted pesticides are known to have been extensively used in agriculture in Egypt. The pesticide residues were determined by HPLC system. This protocol addresses the detection of trace amounts of these pesticides in water and optimizes the conditions for SPE technique compared with the commercial SPE of Supelco Sigma product.

\section{Materials and Methods}

2.1. Chemicals. Low molecular weight of acid-soluble chitosan $\left(3.60 \times 10^{5} \mathrm{Da}\right.$ and $88 \%$ degree of deacetylation), glutaraldehyde (50\%), epichlorohydrin (99\%), toluene, dimethylformamide, and ethyl acetate were purchased from Sigma-Aldrich Co (St. Louis, Missouri, USA). HPLC-grade of acetonitrile, methanol, and water were purchased from Carlo-Erba Reagents SAS, Co (Chaussee du Vexin, 27100 Val-de-Reuil, France). Zinc oxide ( $\mathrm{ZnO})$, red copper (I) oxide $\left(\mathrm{Cu}_{2} \mathrm{O}\right)$, acetic acid, nitric acid, and sodium hydroxide were purchased from El-Gomhoria for pharmaceutical and chemicals Co (Adeb Ishak St, Manshia, Alexandria, Egypt) and used without further purification.

2.2. Technical Pesticides. Technical grade of abamectin ( $96 \%$ purity) was purchased from Merck and Co., Inc., (Kenilworth, New Jersey, USA). Chlorpyrifos methyl (97\%) was purchased from Dow Chemical Co., (Midland, Michigan, USA). Diazinon (90\%) was purchased from Syngenta International AG Co, (Schwarzwaldallee 215, 4002 Basel, Switzerland). Fenamiphos (90\%) was purchased from Miles Inc, Co, (8400 Hawthorn Road, Stilwell, Kansas City, USA). Imidacloprid (96\%) was purchased from Bayer AG Co (51368 Leverkusen, Germany). Lambda-cyhalothrin (97\%) was purchased from Syngenta International AG Co (Schwarzwaldallee 215, 4002 Basel, Switzerland). Methomyl (98\%) was purchased from E.I. du Pont de Nemours and Co (Wilmington, Delaware 19805, USA) and thiophanate-methyl (94\%) 
was purchased from Pennwalt Ltd, Co, (D-221, M.I.D.C, T.T.C. Industrial Area, Thane Belapur Road, Nerul, Navi Mumbai, Maharashtra, India). The chemical structures of these pesticides are shown in Figure S1.

2.3. Instruments and Equipment. High-Performance Liquid Chromatography (HPLC) Agilent technology infinity 1260 (Germany) equipped with an Agilent variable wavelength ultraviolet detector (VWD) was used. The system consists of a quaternary gradient solvent pump to control the flow rate of the mobile phase and an autosampler for automatic injection with a $100 \mu \mathrm{L}$ sample loop, a vacuum degasser, and a column oven $\left(5-80^{\circ} \mathrm{C}\right)$. Separation was performed on ZORBAX Eclipse Plus C18 analytical column $(250 \times$ $4.6 \mathrm{~mm}$ id, $5 \mu \mathrm{m}$ particle size). Data were managed using HP Chemstation software. Perkin Elmer FT-IR Spectrophotometer L160000A with detector $\mathrm{LiTaO}_{3}$, PerkinElmer, Inc, (Waltham, Massachusetts, USA); Malvern Zeta-Nano-sizer, using Laser Doppler Micro-Electrophoresis Malvern instrument Ltd Co (Enigma Business Park, Grove wood Road, Malvern WR14 1XZ, UK); UV-visible Spectrophotometer Alpha 1502 (Laxco, Inc., Bothell, WA 98021, USA); scanning electron microscope (SEM) JSM5300, JEOL Ltd, (Akishima, Tokyo, Japan); transmission electron microscope (TEM) JEOL JEM-1400 (USA); Bruker's X-ray diffraction (XRD, USA); ultrasonic homogenizer HD 2070 with HF generator (GM 2070), ultrasonic converter UW 2070, booster horn (SH $213 \mathrm{G}$ ), and probe microtip MS 73, $\varnothing 3 \mathrm{~mm}$, BANDELIN electronic GmbH \& Co. (KG. Heinrichstraße, Berlin, Germany); hotplate with magnetic stirrer, IKA-Werke GmbH \& Co (Breisgau-Hochschwarzwald, Germany); oven, Heraeus Co (KG-Hanau, Germany); and electric balances three and four digits, BL-410SLCD, Setra systems Inc, (59 Swanson Rd, Boxborough, MA 01719, USA) were used.

2.4. Preparation of Chitosan-Metal Oxide Nanoparticles (ChMO NPs). Ch-MO NPs including chitosan-copper oxide $(\mathrm{Ch}-\mathrm{CuO})$ and chitosan-zinc oxide $(\mathrm{Ch}-\mathrm{ZnO})$ nanoparticles were prepared according to the method of Dehaghi and others with minor modifications [25]. A weight (4g) of chitosan was dissolved in $100 \mathrm{~mL}$ aqueous acetic acid solution $(1 \%, \mathrm{v} / \mathrm{v})$ and stirred for $2 \mathrm{~h}$ using magnetic stirrer (solution A). The desired amount of metal oxide $(1 \mathrm{~mol}$ metal ions per 1 mol amino group of chitosan) was added to the solution. In the case of $\mathrm{Ch}-\mathrm{Cu}$ complex, $\mathrm{Cu}_{2} \mathrm{O}(7.09 \mathrm{~g})$ was dissolved in $20 \mathrm{~mL}$ diluted nitric acid (2\%, v/v) (solution $\mathrm{B}$ ); however, in the case of $\mathrm{Ch}-\mathrm{Zn}$ complex, $\mathrm{ZnO}(8 \mathrm{~g})$ was dissolved in $10 \mathrm{~mL}$ concentrated nitric acid (solution $\mathrm{C}$ ). Solution $\mathrm{B}$ or $\mathrm{C}$ was added dropwise to the solution A using a syringe under continuous stirring for $2 \mathrm{~h}$ until the metal ions conjugated with a chitosan polymer. After that, $12 \mathrm{~mL}$ of glutaraldehyde $(50 \%, v / v)$, as a first crosslinking agent, was added dropwise to the mixture under stirring, followed by addition of $8 \mathrm{~mL}$ epichlorohydrin (99\%) as a second crosslinking agent, under continuous stirring. The $\mathrm{pH}$ was adjusted to 10 by $\mathrm{NaOH}(1 \mathrm{~N})$ dropwise by syringe under stirring. The reaction mixture was then sonicated for $15 \mathrm{~min}$ at a sonication power of $10 \mathrm{kHz}$ and pulses or cycles ( 9 cycle / sec). Finally, the solution was stored in a water bath at $60^{\circ} \mathrm{C}$ for $3 \mathrm{~h}$ until precipitation. The precipitate was filtered, washed with distilled water, and dried at $70^{\circ} \mathrm{C}$ for $3 \mathrm{~h}$.

\subsection{Characterizations of Ch-MO NPs}

2.5.1. Scanning Electron Microscope (SEM). The samples of Ch-MO NPs were investigated using a JEOL SEM with a magnification of $20000 \mathrm{x}$ and acceleration voltage of $19 \mathrm{kV}$. The dry particles were suspended in ethyl alcohol by sonication in dismantling the assembled particles. After that, the particles were mounted on metal stubs with double-sided tape, sputtered with gold, and viewed in an SEM.

2.5.2. Transmission Electron Microscope (TEM). TEM observation was performed on a JEOL JEM-1400 electron microscope (USA) at accelerating voltage of $120 \mathrm{kV}$. Specimens for TEM measurements were prepared by depositing a drop of colloid solution on a 400 mesh copper grid coated by an amorphous carbon film and evaporating the solvent in air at room temperature.

2.5.3. X-Ray Diffraction (XRD). X-ray diffractograms on powder samples were obtained using a Bruker's X-ray diffraction (USA) with $\mathrm{Cu}$ tube radiation $(k=1.54184 \AA)$, a graphite monochromator and Lynxeye detector at $30 \mathrm{kV}$, and a current of $10 \mathrm{~mA}$. The diffractometer was controlled and operated by a PC computer with the DIFFRAC.SUITE ${ }^{\mathrm{TM}}$ software package. Measurements were taken over an angular range of $0.99^{\circ} \leq$ $2 \theta \leq 89.99^{\circ}$ with a scanning step of 0.05 and a fixed counting time of $10 \mathrm{~s}$. Divergence, scattered, and receiving radiation slits were $1^{\circ}, 1^{\circ}$, and $0.2 \mathrm{~mm}$, respectively.

2.5.4. Zeta Potential. The surface charge of Ch-MO NPs was investigated by a Malvern Zeta-Nano-sizer instrument. The fixed weight $(0.1 \mathrm{gm})$ of the prepared particles was suspended in glycerol (50\%) in isopropanol (v/v) and then they were sonicated for $30 \mathrm{~min}$. The suspension was transferred to zeta potential cell [32].

2.5.5. FT-IR Spectroscopy. The functional groups of $\mathrm{Ch}-\mathrm{MO}$ NPs was analyzed by FT-IR spectroscopy with $\mathrm{KBr}$ discs (5 mg of Ch-MO NPs and $100 \mathrm{mg} \mathrm{KBr}$ pellets), in the range from 4000 to $400 \mathrm{~cm}^{-1}$, with a resolution of $4.0 \mathrm{~cm}^{-1}$ on a Perkin Elmer 1600 FT-IR Spectrophotometer (USA) [20].

2.6. Kinetic Study. The preliminary study was conducted to investigate the influence of some factors ( $\mathrm{pH}$ of the solution, temperature, and agitation time) on the adsorption efficiency of imidacloprid (as a pesticide example) on $\mathrm{Ch}-\mathrm{CuO}$ NPs using full factorial design in MINITAB ${ }^{\circledR}$ software v17.1.0, 2002 (Minitab Inc, Co., Pine Hall Rd, State College, PA 16801-3008, USA). The three factors were tested at three levels including low level, high level, and medium level, coded as $-1,+1$, and 0 , respectively. The minimum number of experimental runs that have to be carried out for two levels with three factors design is $2^{3}=8$ runs plus 1 run at a center point. The experiments were carried out using $100 \mathrm{mg}$ of each type of nanoparticles suspended in $25 \mathrm{~mL}$ of imidacloprid solution $(25 \mathrm{mg} / \mathrm{L})$ at 10 , 25, and $40^{\circ} \mathrm{C}, \mathrm{pH} 5,7$, and 9, and different agitation times 


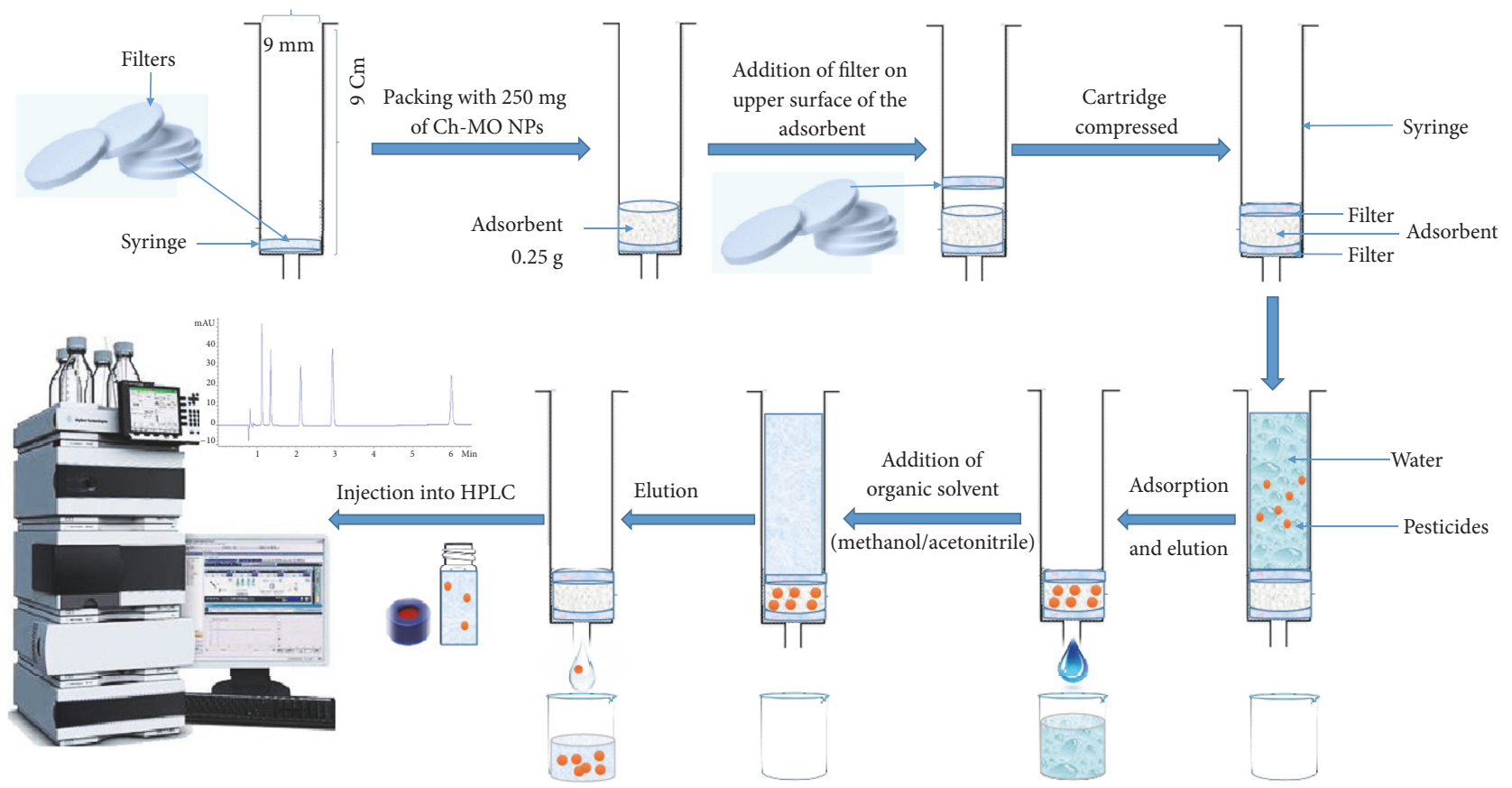

FIGURE 1: A schematic diagram shows extraction and clean-up of pesticides using SPE cartridge packed with Ch-MO NPs (Ch-CuO NPs and $\mathrm{Ch}-\mathrm{ZnO}$ NPs). This figure is reproduced from Badawy et al. (2018) (under the Creative Commons Attribution License/public domain).

(10, 25 and $40 \mathrm{~min})$ with shaking at $150 \mathrm{rpm}$. The blank samples were added and placed in the same shaker to avoid loss of evaporation of pesticide or solvent. After each time with different experiments, the eluent was determined by HPLC $[2,25,33]$.

2.7. Solid-Phase Extraction (SPE) of Different Pesticides by Ch-MO NPs. The prepared nanoparticles were studied as solid matrix materials in SPE cartridge. The SPE cartridge was performed using a plastic syringe column of $0.9 \mathrm{~cm}$ diameter and $9 \mathrm{~cm}$ in length (Figure 1). The column was filled up without gaps by compressing a frit on the bottom and then adding $0.25 \mathrm{~g}$ of each Ch-MO NPs and stopcock frit on the upper [34]. We compared these cartridges with the ODS (C18, Supelco) cartridge as it is the most common material used in extraction and clean-up of pesticide residues. Three different concentrations (10,50, and $100 \mathrm{mg} / \mathrm{L})$ of each pesticide (abamectin, diazinon, fenamiphos, imidacloprid, lambda-cyhalothrin, methomyl, and thiophanatemethyl) were prepared by dissolving the tested pesticide in a minimum volume of methanol and then completed to the final volume of $20 \mathrm{~mL}$ with water. The prepared solutions were allowed to pass through the SPE cartridge. After that, the adsorbed amount of each pesticide was eluted by $5 \mathrm{~mL}$ of acetonitrile/methanol (1:1, v/v).

2.8. HPLC Analysis. The water phase (effluent) and organic phase (eluent) were collected from SPE cartridge and injected into HPLC. The summary of the optimum conditions for chromatographic analysis of each pesticides is presented in Table S1. For analysis calibration, five standard solutions of each pesticide were prepared by dissolving weighed amount in the mobile phase used for each pesticide, and different quantities $(0.0125-0.15 \mu \mathrm{g} / \mathrm{mL})$ were injected into HPLC. Calibration curves were constructed by plotting the peak areas of compound against the amount injected in $\mu \mathrm{g}$. Regression analysis of the data $(n=5)$ for each calibration curve gave the values of slope, along with the intercept and correlation coefficient. Calibration curves were used for the quantification of the pesticides in water samples. The limit of detection (LOD) and limit of quantification (LOQ) for each pesticide were calculated. The LOD is the lowest concentration of the analyte in a sample that can still be detected by the analytical method but should not be quantified as an appropriate value. However, the LOQ is the lowest concentration of the sample that can still be quantitatively detected with acceptable precision and accuracy [35]. LOD was defined as $3 \sigma / \mathrm{S}$ and LOQ was defined as $10 \sigma / \mathrm{S}$, where $\sigma$ is the standard deviation and $\mathrm{S}$ is the slope of the calibration curve [36].

2.9. Statistical Analysis. The statistical analysis was performed using the SPSS 25.0 software (Statistical Package for Social Sciences, USA). Analysis of variance (ANOVA) of the data was conducted, and means property values were separated by Student-Newman-Keuls (SNK) test. Differences were considered significant at $\mathrm{p} \leq 0.05$. The statistical analysis of adsorption kinetics was investigated by full factorial design using a MINITAB ${ }^{\circledR}$ software v17.1.0, 2002 (Minitab Inc, Co., Pine Hall Rd, State College, PA 16801-3008, USA).

\section{Results and Discussion}

3.1. Preparation of Ch-MO NPs. The Ch-MO NPs were synthesized through combining the sol-gel precipitation and 
TABLE 1: Reaction conditions and characterizations of chitosan-metal oxide nanoparticles (Ch-MO NPs).

\begin{tabular}{|c|c|c|c|c|c|c|}
\hline Product code & Reaction components & Mole ratio & $\begin{array}{l}\text { Product } \\
\text { color }\end{array}$ & Yield (\%) & $\begin{array}{c}\text { Particles diameter }(\mathbf{n m}) \\
\pm \mathrm{SE} \\
\end{array}$ & $\begin{array}{c}\text { Zeta-potential } \\
(\mathbf{m V})\end{array}$ \\
\hline Ch-CuO NPs & $\begin{array}{c}\text { Chitosan: } \mathrm{Cu}_{2} \mathrm{O} \text { : Glutaraldehyde: } \\
\text { Epichlorohydrin }\end{array}$ & $1: 2: 2: 3$ & $\begin{array}{l}\text { Yellowish- } \\
\text { dark }\end{array}$ & 85.29 & $93.74 \pm 5.70$ & +0.516 \\
\hline Ch-ZnO NPs & $\begin{array}{c}\text { Chitosan: } \mathrm{ZnO} \text { : Glutaraldehyde: } \\
\text { Epichlorohydrin }\end{array}$ & $1: 4: 2: 3$ & Yellowish & 91.67 & $97.95 \pm 9.46$ & +0.086 \\
\hline
\end{tabular}

crosslinking mechanism [27] as illustrated in Figure S2. Monodispersed metal oxide particles were coated by chitosan as the uniform of core or shell layer. They were then sequentially crosslinked with glutaraldehyde and epichlorohydrin. Firstly, glutaraldehyde forms the hard-spherical shape of particles through reaction with the amino groups of chitosan. In the second stage, the epichlorohydrin reacted with the hydroxyl groups to give more hardness for particles and reduce the hydrophilicity of chitosan. The final product was precipitated by aqueous solution of $\mathrm{NaOH}(1 \mathrm{~N})$. The yields were $85.29 \%$ and $91.67 \%$ for $\mathrm{Ch}-\mathrm{CuO} \mathrm{NPs}$ and $\mathrm{Ch}-\mathrm{ZnO}$ NPs, respectively, with a yellowish and dark yellowish color, respectively (Table 1$)$.

Many research articles prepared and characterized polymer-supported metals and metal oxide nanoparticles including chitosan- $\mathrm{ZnO}$ and chitosan- $\mathrm{CuO}$, and some of which suggested the previous mechanism of the particle formation [26, 37]. For example, Shrifian-Esfahni et al. prepared and characterized $\mathrm{Fe}_{3} \mathrm{O}_{4}$ /chitosan core-shell and the mechanism investigated hydrogen-bonding formation. In addition, the authors indicated the unbonded hydroxyl groups with partial positive charges surrounding nanoparticle [37]. Therefore, we completed this reaction in our study by crosslinking agent to cover the reactive functional groups (amino and hydroxyl). Recently, we prepared chitosansiloxane magnetic nanoparticles from $\mathrm{Fe}_{3} \mathrm{O}_{4}$ functionalized by siloxane derivatives followed by coating with chitosan through a crosslinking mechanism using glutaraldehyde and epichlorohydrin [34].

\subsection{Characterizations of Ch-MO NPs}

3.2.1. Scanning Electron Microscope (SEM). The SEM was used to investigate the surface morphology and particle size of Ch-CuO NPs and Ch-ZnO NPs as shown in Figures 2(a) and 2(b), respectively. The particles in nanocomposites were found with almost spherical morphology with aggregations of the nanoparticles. Nanoparticles were measured with an average size of 93.74 and $97.95 \mathrm{~nm}$ for $\mathrm{Ch}-\mathrm{CuO}$ NPs and Ch-ZnO NPs, respectively (Table 1). Dehaghi and coauthors prepared $\mathrm{Ch}-\mathrm{ZnO}$ NPs without crosslinking reaction and they found that the particles size was in a arrange of $58 \mathrm{~nm}$ [25]. However, Manikanndan and others prepared the $\mathrm{Ch}-\mathrm{Cu}$ complex without crosslinking reactions with an average size ranging from 20 to $30 \mathrm{~nm}$ [38]. Gouda and Hebeish loaded $\mathrm{CuO}$ NPs into chitosan by using drops of $\mathrm{H}_{2} \mathrm{O}_{2}(30 \%)$ and then stirring with a high-speed homogenizer at $10000 \mathrm{rpm}$ for $30 \mathrm{~min}$. The corresponding $\mathrm{CuO} /$ chitosan nanocomposite formed was characterized by using transmission electron microscope (TEM) images and they presented a very homogeneous morphology with a quite uniform particle size distribution and a rather spherical shape [39]. The particle size diameters obtained were $10 \mathrm{~nm}$ for chitosan nanoparticle and $20 \mathrm{~nm}$ for $\mathrm{CuO} /$ chitosan nanocomposite.

3.2.2. Transmission Electron Microscope (TEM). TEM photographs of $\mathrm{Ch}-\mathrm{CuO} \mathrm{NPs}$ and $\mathrm{Ch}-\mathrm{ZnO} \mathrm{NPs}$ are presented in Figures 2(c) and 2(d), respectively. It is evident that the particles are formed with average sizes ranging from 75 to $100 \mathrm{~nm}$. In addition, the nanoparticles of both products showed high agglomeration of smaller size nanoparticles and their surface was rough and porous because metal oxide particles were wrapped by chitosan matrix.

3.2.3. X-Ray Powder Diffraction (XRD). The X-ray diffraction patterns of Ch-MO NPs are shown in Figure 3. Figure 3(a) shows the characteristic peaks at $2 \theta \sim 10^{\circ}$ and $2 \theta \sim$ $20^{\circ}$, due to inter- and intramolecular hydrogen bonds in chitosan molecule [40, 41]. However, these two peaks are very weak in the spectra of $\mathrm{Ch}-\mathrm{CuO} \mathrm{NPs}$ and $\mathrm{Ch}-\mathrm{ZnO}$ NPs (Figures 3(b) and 3(c), respectively), which suggest a low crystallinity and an amorphous nature of the products. The weak peaks reflect great disarray in chain alignment of chitosan with the production of new peaks identifying zinc oxide and copper oxide. The X-ray diffraction patterns of $\mathrm{Ch}$ $\mathrm{CuO}$ NPs (Figure 3(b)) demonstrated diffraction angles of $23.58^{\circ}, 26.08^{\circ}, 29.98^{\circ}, 33.67^{\circ}, 39.87^{\circ}, 53.35^{\circ}$, and $77.80^{\circ}$, which correspond to the characteristic face centered $\mathrm{CuO}$ core with counts index (260), (415), (240), (458), (255), (149), and (110), respectively $[42,43]$. The diffraction angles observed at $10.86^{\circ}$ and $20.34^{\circ}$ corresponding to count indexes (134) and (250), respectively, refer to the chitosan shell. The main peaks of $\mathrm{Ch}-\mathrm{ZnO} \mathrm{NPs}$ (Figure $3(\mathrm{c})$ ) were at $2 \theta=30.91^{\circ}$, $33.55^{\circ}, 35.42^{\circ}, 46.71^{\circ}, 55.80^{\circ}, 62.08^{\circ}, 67.22^{\circ}$, and $68.28^{\circ}$, which correspond to the (1159), (1023), (1563), (391), (566), (449), (411), and (258) crystal planes, respectively. These peaks are consistent with the database in Joint Committee on Powder Diffraction Standards for ZnO (JCPDS file, PDF No. 36-1451) [44]. In addition, two smaller peaks at $2 \theta=76.31^{\circ}$ and $88.84^{\circ}$ corresponding to the count (157) and (170), respectively, were also observed. The diffraction angles observed at $10.98^{\circ}$ and $20.76^{\circ}$ corresponding to count indexes (211) and (289), respectively, refer to the chitosan shell.

3.2.4. Zeta Potential. Zeta potential is the surface charge value and it is a key indicator of the stability of colloidal 


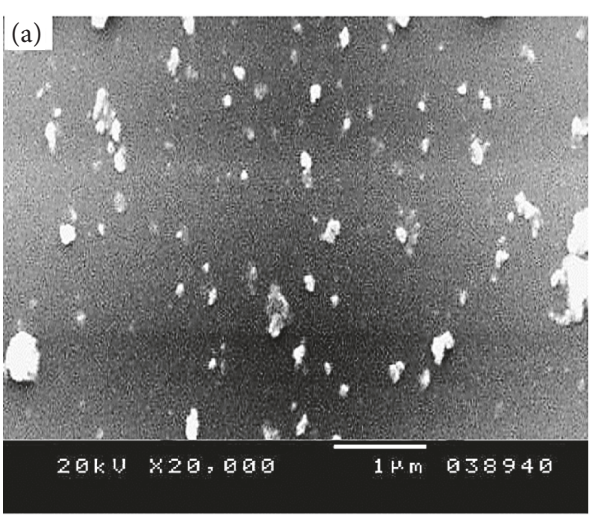

(a)

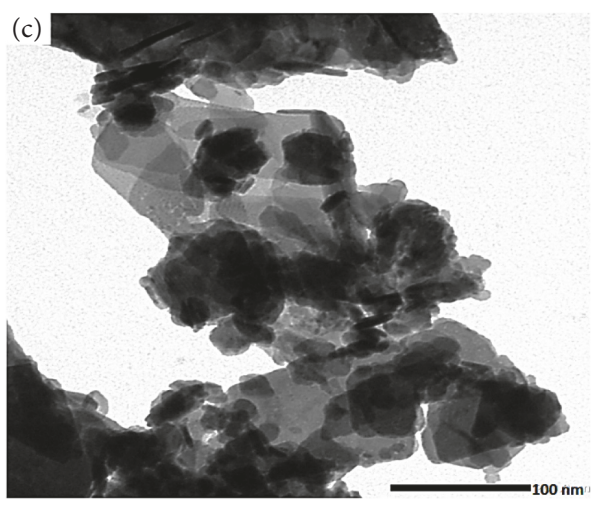

(c)

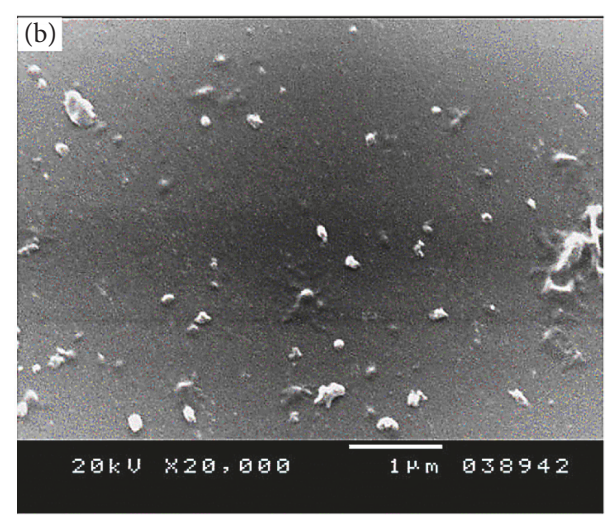

(b)

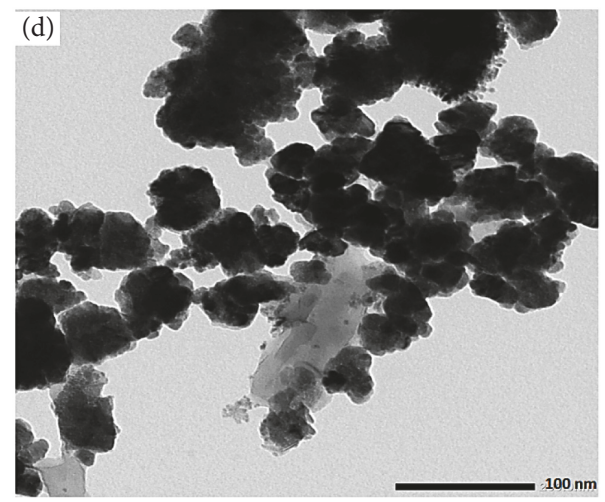

(d)

Figure 2: Electron microscopy images of Ch-MO NPs. (a), (b) The SEM of Ch-CuO NPs and Ch-ZnO NPs, respectively. (c), (d) The TEM of Ch-CuO NPs and Ch-ZnO NPs, respectively. Scale bar for SEM measurements was $1 \mu \mathrm{m}$ and magnification x20000 at $20 \mathrm{Kv}$. Scale bar for TEM measurements was $100 \mathrm{~nm}$ and magnification $\times 40000$ at $20 \mathrm{Kv}$.

dispersions. The magnitude of the zeta potential indicates the degree of electrostatic repulsion between charged particles in a dispersion. For molecules and particles that are small enough, a high zeta potential will confer stability; i.e., the solution or dispersion will resist aggregation $[32,45]$. In the present study, the values were $+0.516 \mathrm{mV}$ for $\mathrm{Ch}-\mathrm{CuO} \mathrm{NPs}$ and $+0.086 \mathrm{mV}$ for Ch-ZnO NPs (Table 1 and Figure S3), indicating a rapid coagulation or flocculation of particles in suspension at $\mathrm{pH} 7$ and $25^{\circ} \mathrm{C}$. It can be noted that the nanoparticles of $\mathrm{Ch}-\mathrm{CuO}$ NPs have a higher charge $(\approx 5$ fold) than Ch-ZnO NPs. The positive charge of zeta potential values obtained refers to the surface charge of the particles. The previous study reported that the $\mathrm{Ch}-\mathrm{Cu}$ complex has a negative charge (-29 mv) [38]. However, the Ch-Zn complex had a positive charge $(+26.6)$ [46]. The low surface charge of the prepared nanoparticles ( $\mathrm{Ch}-\mathrm{CuO}$ and $\mathrm{Ch}-\mathrm{ZnO}$ ) may be due to the crosslinking reaction that blocked the hydroxyl and amino functional groups. The glutaraldehyde blocks the amino groups of chitosan while the hydroxyl groups were blocked by epichlorohydrin $[29,47,48]$.

3.2.5. FT-IR. The FT-IR spectra of chitosan and Ch-MO NPs are shown in Figure 4. The spectrum of pure chitosan exhibits bands at $3436 \mathrm{~cm}^{-1}$ due to the stretching vibration mode of $-\mathrm{OH}$ and $-\mathrm{NH}_{2}$ groups. The peak at $2924 \mathrm{~cm}^{-1}$ is a type of $\mathrm{C}-\mathrm{H}$ stretching vibration, while the band at $1655 \mathrm{~cm}^{-1}$ is due to the amide I group (C-O stretching along with $\mathrm{N}$ $\mathrm{H}$ deformation mode). A band at $1590 \mathrm{~cm}^{-1}$ is attributed to the $\mathrm{NH}_{2}$ group due to $\mathrm{N}-\mathrm{H}$ deformation, while a band at $1419 \mathrm{~cm}^{-1}$ is due to C-N axial deformation (amine group band). In addition, the peak at $1380 \mathrm{~cm}^{-1}$ peak is due to the $\mathrm{COO}^{-}$group in carboxylic acid salt, and the band at $1160 \mathrm{~cm}^{-1}$ is assigned to the special broad peak of $\beta(1-4)$ glucosidic bond in polysaccharide unit. However, the peak at $1080 \mathrm{~cm}^{-1}$ is attributed to the stretching vibration mode of the hydroxyl group, $989-1060 \mathrm{~cm}^{-1}$ stretching vibrations of C-O$\mathrm{C}$ in glucose units [20].

The FT-IR spectrum of Ch-ZnO NPs exhibits band at $3401 \mathrm{~cm}^{-1}$ due to the combination between $-\mathrm{OH}$ and $-\mathrm{NH}_{2}$ groups. The peak at $2932 \mathrm{~cm}^{-1}$ is a typical of C-H stretch vibration. The band at $1657 \mathrm{~cm}^{-1}$ is due to the rest of amide I group while a band at $1553 \mathrm{~cm}^{-1}$ is attributed to the $\mathrm{NH}_{2}$ group due to $\mathrm{N}-\mathrm{H}$ deformation. The peak at $1407 \mathrm{~cm}^{-1}$ is due to C-N axial deformation (amine group band). In addition, the band at $1067 \mathrm{~cm}^{-1}$ is attributed to the stretching vibration mode of the hydroxyl group and the band at $682 \mathrm{~cm}^{-1}$ ascribed to the vibration of $\mathrm{O}-\mathrm{Zn}-\mathrm{O}$ core groups. 


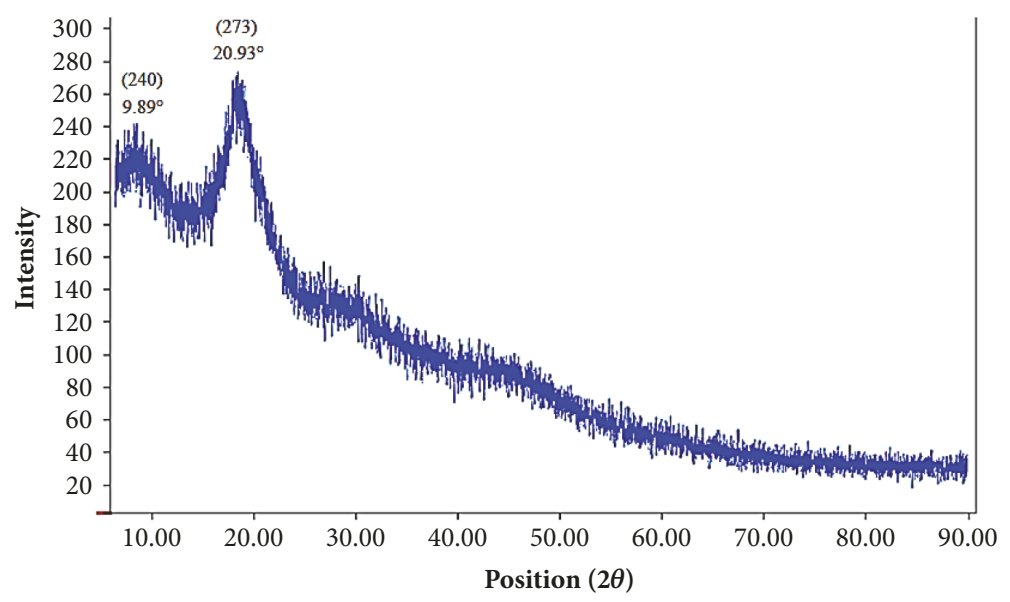

(a)

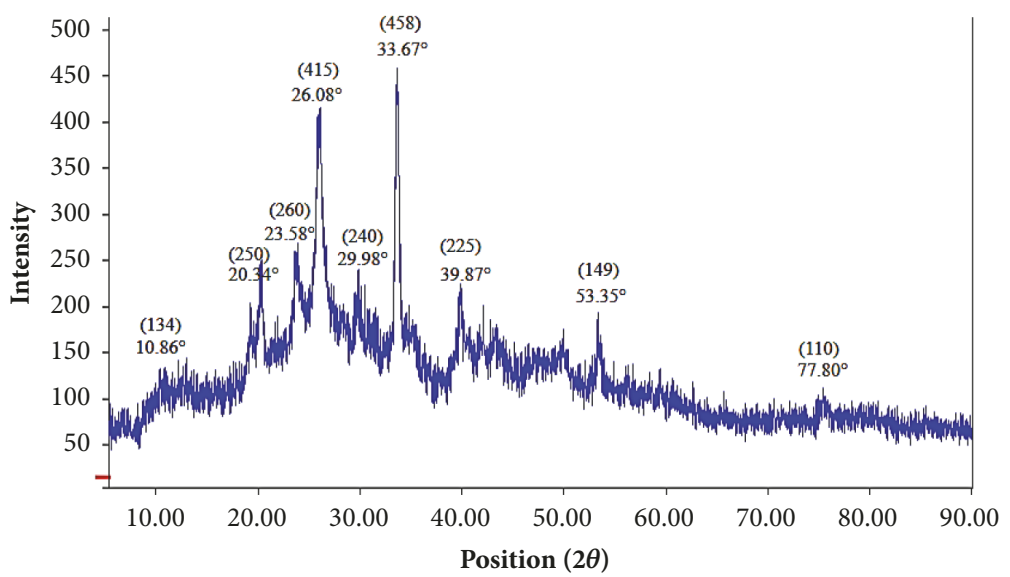

(b)

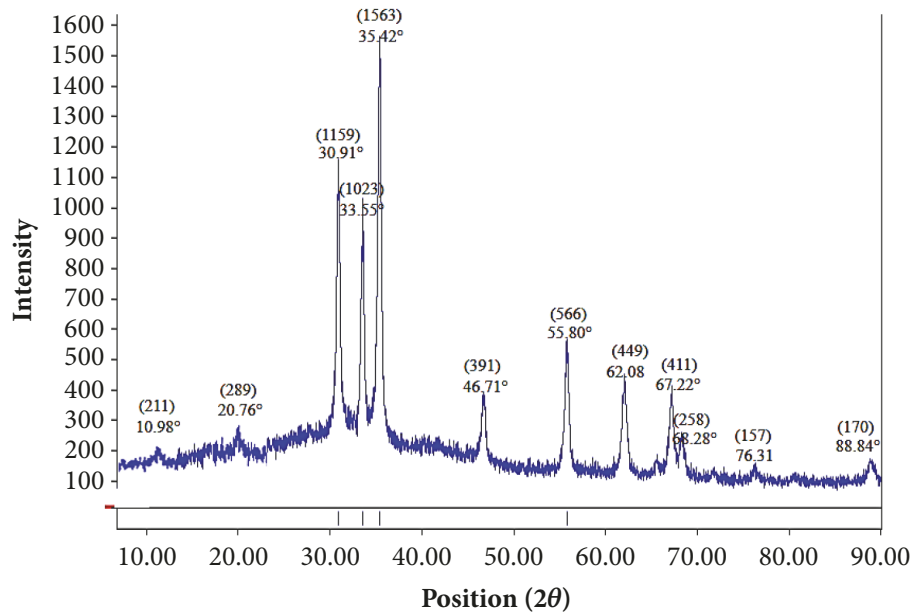

(c)

Figure 3: X-ray diffraction (XRD) patterns of chitosan (a), Ch-CuO NPs (b), and Ch-ZnO NPs (c).

The spectrum of $\mathrm{Ch}-\mathrm{CuO}$ NPs exhibits bands at $3390 \mathrm{~cm}^{-1}$ due to the combination between $-\mathrm{OH}$ and $-\mathrm{NH}_{2}$ groups. The peak at $2924 \mathrm{~cm}^{-1}$ indicates a C-H stretching vibration. A band at $1583 \mathrm{~cm}^{-1}$ is attributed to the $\mathrm{NH}_{2}$ group due to $\mathrm{N}-\mathrm{H}$ deformation, and $1410 \mathrm{~cm}^{-1}$ peak is due to $\mathrm{C}-\mathrm{N}$ axial deformation (amine group band). A band at $1380 \mathrm{~cm}^{-1}$ is due to the COO- group in carboxylic acid salt, while the peak at $1070 \mathrm{~cm}^{-1}$ is attributed to the stretching vibration mode of the hydroxyl group. The band at $682 \mathrm{~cm}^{-1}$ is attributed to the vibration of $\mathrm{O}-\mathrm{Cu}-\mathrm{O}$ core groups. However, the peak at 493 is ascribed to $\mathrm{Cu}-\mathrm{O}$ bond vibration. 
TABLE 2: Experimental design using Minitab software and standardized effects of temperature, $\mathrm{pH}$, and time on the adsorption of imidacloprid insecticide at $25 \mathrm{mg} / \mathrm{L}$ on $\mathrm{Ch}-\mathrm{CuO}$ NPs.

\begin{tabular}{lcccc}
\hline Run order & Temperature $\left({ }^{\circ} \mathbf{C}\right)$ & pH & Time (min) & Adsorption (\%) \pm SE \\
\hline 1 & 10 & 5 & 10 & $12.18 \pm 0.58$ \\
2 & 40 & 5 & 10 & $31.86 \pm 1.16$ \\
3 & 10 & 9 & 10 & $62.21 \pm 0.62$ \\
4 & 40 & 9 & 10 & $84.24 \pm 0.78$ \\
5 & 10 & 5 & 40 & $19.23 \pm 1.77$ \\
6 & 40 & 5 & 40 & $27.93 \pm 2.01$ \\
7 & 10 & 9 & 40 & $92.91 \pm 1.72$ \\
8 & 40 & 9 & 40 & $100.00 \pm 0.00$ \\
9 & 25 & 7 & 25 & $87.43 \pm 0.98$ \\
\hline
\end{tabular}

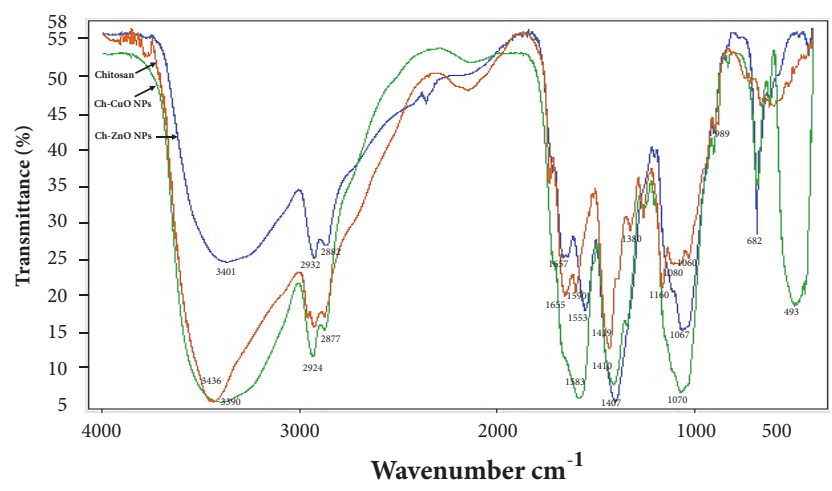

FIGURE 4: FT-IR spectra of chitosan (A), chitosan-copper oxide nanoparticles (Ch-CuO NPs), and chitosan-zinc oxide nanoparticles (Ch-ZnO NPs).

In comparison with chitosan, the broader and stronger peak shifted considerably to lower wave number at $3390 \mathrm{~cm}^{-1}$ in Ch-CuO NPs and $3401 \mathrm{~cm}^{-1}$ in Ch-ZnO NPs, which indicates strong attachment of metal oxide to the amide groups of chitosan molecules (Figure 4). The absorption peaks at 2877-2924 in Ch-MO NPs are due to asymmetric stretching of $\mathrm{CH}_{2}$ and $\mathrm{CH}_{3}$ of chitosan polymer and the overlapping with - NH. The absorption peaks at 1583 and $1070 \mathrm{~cm}^{-1}$ in the spectrum of $\mathrm{Ch}-\mathrm{CuO}$ NPs are attributed to bending vibration of the - $\mathrm{NH}$ group and the $\mathrm{C}-\mathrm{O}$ stretching group but these peaks were observed at 1553 and $1067 \mathrm{~cm}^{-1}$ in spectrum of Ch-ZnO NPs. New broad absorption bands at 682 and $400 \mathrm{~cm}^{-1}$ were found in the FT-IR spectra of ChMO NPs which were ascribed to the vibration of $\mathrm{O}-\mathrm{Cu}-\mathrm{O}$ and $\mathrm{O}-\mathrm{Zn}-\mathrm{O}$ groups $[49,50]$.

3.3. Kinetic Studies of Adsorption Efficiency of Pesticides by Ch-MO NPs. Three factors ( $\mathrm{pH}$, temperature, and agitation time) were studied on the efficiency of Ch-CuO NPs in the adsorption of imidacloprid insecticide at $25 \mathrm{mg} / \mathrm{L}$. The full factorial design was used in terms of the experimental runs, and the experimental data are shown in Table 2 . The results indicate that the $\mathrm{pH}$ values of 7 and 9 showed the most significant effect on the adsorption efficiency of imidacloprid with $62.21,84.24,92.91,100$, and 87.43 for run $3,4,7,8$, and

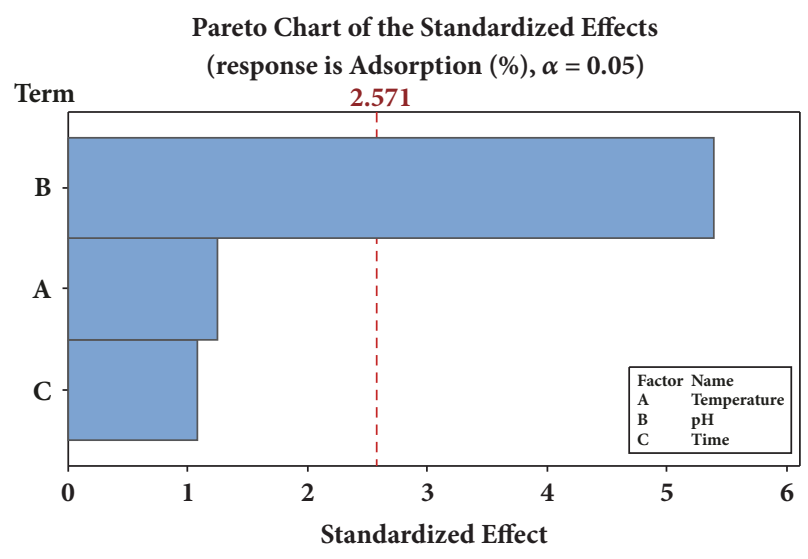

Figure 5: Pareto Chart of the standardized effects of $\mathrm{pH}$, temperature, and time of adsorption (response is adsorption (\%), $\alpha=0.05$ ).

9, respectively. To investigate the main effect of all factors, the adsorption efficiency was studied using the Pareto chart and the result is shown in Figure 5. The most affecting factor is the $\mathrm{pH}$ followed by temperature and then agitation time. The Pareto chart provides a clear visualization of the factor effects and indicates that the $\mathrm{pH}$ has the most significant effect on the adsorption at $\alpha=0.05$; however, the temperature and agitation time did not show values lower than the reference line $(2.571$ at $\alpha=0.05)$ [2, 25]. From this analysis, the adsorption (\%) can be calculated or predicted according to the following model (1).

$$
\begin{aligned}
& \text { Adsorption }(\%)=-73.3+0.479 \text { Temperature } \\
& \begin{aligned}
+15.51 \mathrm{pH}+0.413 \text { Time } \\
\mathrm{S}=16.28 \text { and } \\
\mathrm{R}^{2}=86.40 \%
\end{aligned}
\end{aligned}
$$

It can be noted that the three factors have a positive sign that means that the adsorption will be increased with an increase in each factor. The factor has a greater correlation factor denoting the great effects. Therefore, the $\mathrm{pH}$ has a great effect (coefficient $=15.51$ ) on the adsorption followed in the descending order by temperature (coefficient $=0.479$ ) 
TABLE 3: Statistical data from regression analysis of different pesticides obtained from the study with analytical HPLC methods.

\begin{tabular}{lcccccc}
\hline Pesticide & Rt $(\mathbf{m i n}) \pm \mathbf{S D}$ & $\mathbf{A}_{\mathbf{s}} \pm \mathbf{S D}$ & Regression equation & $\mathbf{R}^{2}$ & $\mathrm{LOD}(\mu \mathrm{g} / \mathrm{mL})$ & $\mathrm{LOQ}(\mu \mathrm{g} / \mathrm{mL})$ \\
\hline Abamectin & $7.999 \pm 0.01$ & $0.871 \pm 0.00$ & $\mathrm{y}=4523.45190 \mathrm{x}-2.70225$ & 0.9998 & 0.023 & 0.077 \\
Diazinon & $7.975 \pm 0.00$ & $0.870 \pm 0.01$ & $\mathrm{y}=1177.60010 \mathrm{x}+0.42100$ & 0.9999 & 0.046 & 0.154 \\
Fenamiphos & $3.374 \pm 0.01$ & $0.885 \pm 0.01$ & $\mathrm{y}=3214.11453 \mathrm{x}+0.89949$ & 0.9997 & 0.002 & 0.006 \\
Imidacloprid & $3.647 \pm 0.00$ & $0.853 \pm 0.04$ & $\mathrm{y}=4728.25710 \mathrm{x}+0.794634$ & 0.9998 & 0.020 & 0.066 \\
Lambda-cyhalothrin & $10.761 \pm 0.05$ & $0.923 \pm 0.05$ & $\mathrm{y}=2874.16095 \mathrm{x}+0.431849$ & 0.9999 & 0.012 & 0.040 \\
Methomyl & $2.795 \pm 0.03$ & $0.953 \pm 0.00$ & $\mathrm{y}=4972.13330 \mathrm{x}+3.61685$ & 0.9997 & 0.018 & 0.059 \\
Thiophanate-methyl & $4.566 \pm 0.01$ & $1.070 \pm 0.00$ & $\mathrm{y}=3412.34475 \mathrm{x}+11.24269$ & 0.9997 & 0.024 & 0.081 \\
\hline
\end{tabular}

Rt: retention time. $\mathbf{A}_{\mathbf{s}}$ : peak asymmetry factor. $\mathbf{R}^{2}$ : linear correlation coefficient. LOD: limit of detection. LOQ: limit of quantification.

and then the agitation time (coefficient $=0.413$ ). In addition, three-dimensional response surface plots are presented in Figure S4. These plots provide useful information about the behavior of the system within the experimental design, which was used to understand the main and interactive effects of the factors. The effect of $\mathrm{pH}$, temperature, and agitation time on pesticides adsorption percentage was shown at initial concentration in Figure S4 right. The results indicated that the adsorption or retention percentage increased with increasing of the $\mathrm{pH}$ and temperature, but the optimum adsorption percentage was observed at $\mathrm{pH} 7$ and temperature of $25^{\circ} \mathrm{C}$. These results are consistent with the previous study, which reported that the removal rate of pyrethrin increased by an increase of $\mathrm{pH}$ to 8 [25]. The adsorption ratio increased at $\mathrm{pH}$ increase and induction time from 10 to $40 \mathrm{~min}$, but the optimal adsorption was performed at $\mathrm{pH} 7$ and after 25 minutes. However, the effect of time and temperature has proved the previous theory that confirmed that optimal temperature and induction time are from $25^{\circ} \mathrm{C}$ to $40^{\circ} \mathrm{C}$ and 25 to 40 minutes, respectively at the top of the surface plot curve. The contour plots shown in Figure S4 indicate the interaction between the $\mathrm{pH}$ and temperature and confirmed that the optimum adsorption was found at $\mathrm{pH}$ ranging from 6.5 to 9 with the optimal temperature from 25 to $40^{\circ} \mathrm{C}$.

3.4. SPE of Pesticides Using Ch-MO NPs and HPLC Analysis. HPLC analytical methods for the tested pesticides were validated by calculating regression equation, correlation coefficient $\left(\mathrm{R}^{2}\right)$, peak asymmetry factor $\left(\mathrm{A}_{\mathrm{s}}\right)$, LOD, and LOQ for each pesticide and the data are presented in Table 3. The values of $\mathrm{R}^{2}$ obtained for the regression lines demonstrate the excellent relationship between peak area and the injected amount of all pesticides $\left(\mathrm{R}^{2} \geq 0.999\right)$. The LOD of the pesticides determined by HPLC ranged from 0.002 to $0.046 \mu \mathrm{g} / \mathrm{mL}$ and the LOQ was in the range of 0.006 to $0.154 \mu \mathrm{g} / \mathrm{mL}$. The asymmetry factor $\left(\mathrm{A}_{\mathrm{s}}\right)$ is an indication for the peak tailing $[51,52]$ being in the range of 0.870 to 1.070 .

The efficacy data of Ch-MO NPs $(250 \mathrm{mg})$ in extraction and removal of pesticides from water samples at three levels $(10,50$, and $100 \mathrm{mg} / \mathrm{L})$ is presented in Tables 4 and 5 for $\mathrm{Ch}-\mathrm{CuO}$ NPs and $\mathrm{Ch}-\mathrm{ZnO}$ NPs, respectively, and compared to the standard ODS cartridge (Supelco) (Table 6). The data are presented as a percentage of that extracted by methanol: acetonitrile (50:50) and that found in water phase. It can be noted that the removal percentages were decreased with the increase of the concentration. Table 4 shows the results of cartridge loaded with $\mathrm{Ch}-\mathrm{CuO}$ NPs. All pesticides were adsorbed into the $\mathrm{Ch}-\mathrm{CuO}$ NPs with high percentages compared to the amount remaining in the water phase. Lambda-cyhalothrin was the highest in removal (98.93, 95.19, and $92.66 \%$ at 10,50 , and $100 \mathrm{mg} / \mathrm{L}$, respectively) followed in the descending order by abamectin (98.02, 94.34, and $92.31 \%$ at 10,50 , and $100 \mathrm{mg} / \mathrm{L}$, respectively). However, there is no significant difference between both insecticides. Fenamiphos showed 95.33, 93.28, and 90.44\% and then imidacloprid with $93.78,90.39$, and $72.91 \%$ at 10,50 , and $100 \mathrm{mg} / \mathrm{L}$, respectively. However, methomyl and thiophanatemethyl showed moderate values (63.85-84.75\%). Diazinon was the lowest pesticide among all the tested pesticides in removal percentages $(70.15,34.21$, and $21.44 \%$ at 10,50 , and $100 \mathrm{mg} / \mathrm{L}$, respectively). Ch-CuO NPs demonstrated that no amount of lambda-cyhalothrin was found in water at any of the tested concentrations. This finding may be due to the fact that the lambda-cyhalothrin has a very low solubility in water and a highest octanol-water partition coefficient value compared to the other tested pesticides [53], followed in the descending order by imidacloprid, thiophanate-methyl, fenamiphos, and abamectin. However, methomyl indicated high percentages in water $(20.55,25.00$, and $33.37 \%$ at 10,50 , and $100 \mathrm{mg} / \mathrm{L}$, respectively). This is may be due to the high solubility of this compound in the water [54].

All pesticides were also adsorbed into the $\mathrm{Ch}-\mathrm{ZnO}$ NPs with high percentage compared to that found in the water phase and lambda-cyhalothrin was the highest in removal with $99.09,98.00,94.47 \%$ at 10,50 , and $100 \mathrm{mg} / \mathrm{L}$, respectively (Table 5 ), followed in the descending order by abamectin, fenamiphos, and imidacloprid. However, diazinon and thiophanate-methyl showed moderate values (60.1094.28\%). Methomyl was the lowest pesticide among all tested pesticides $(41.40,38.51$, and $36.62 \%$ at 10,50 , and $100 \mathrm{mg} / \mathrm{L}$, respectively). These particles proved that the insecticide lambda-cyhalothrin was not detected in water at any of the tested concentrations. However, methomyl showed high percentages in water $(18.09,57.82$, and $62.59 \%$ at 10,50 , and $100 \mathrm{mg} / \mathrm{L}$, respectively).

Table 6 shows the recovery of pesticides at 10,50, and $100 \mathrm{mg} / \mathrm{L}$ from water using the standard SPE cartridge $\left(\mathrm{C}_{18}\right)$ obtained from Supelco. Diazinon, fenamiphos, and thiophanate-methyl were the most pesticides extracted from this type of cartridge in all tested concentrations. However, 


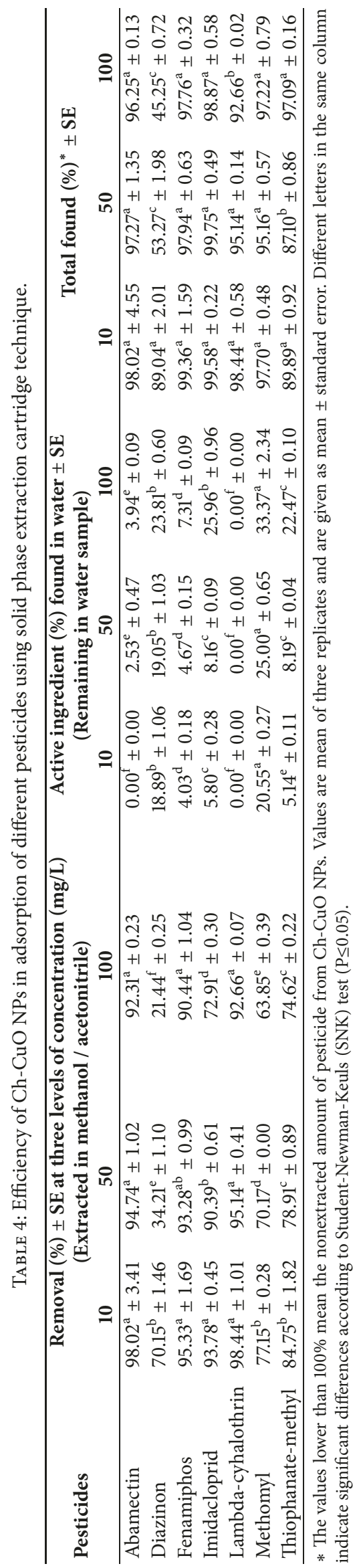




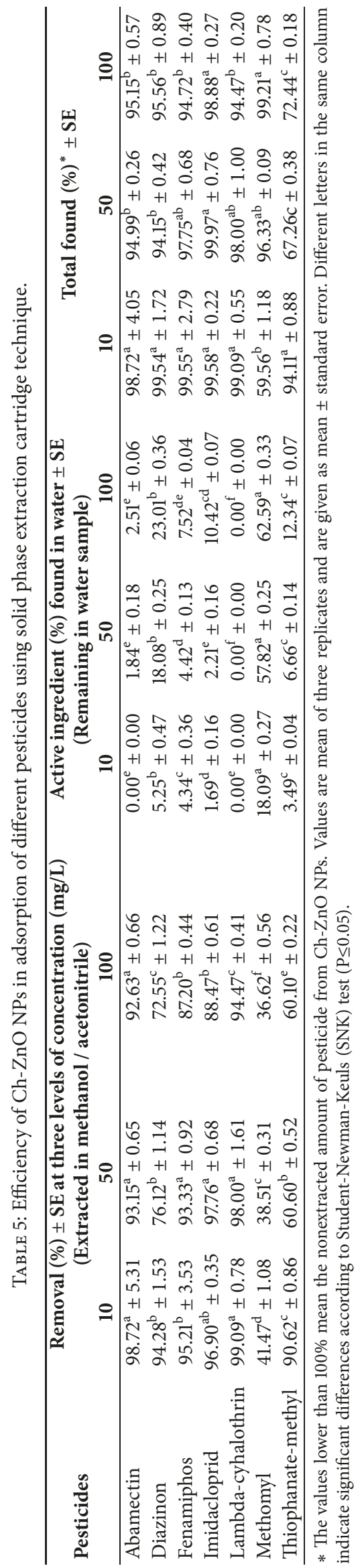




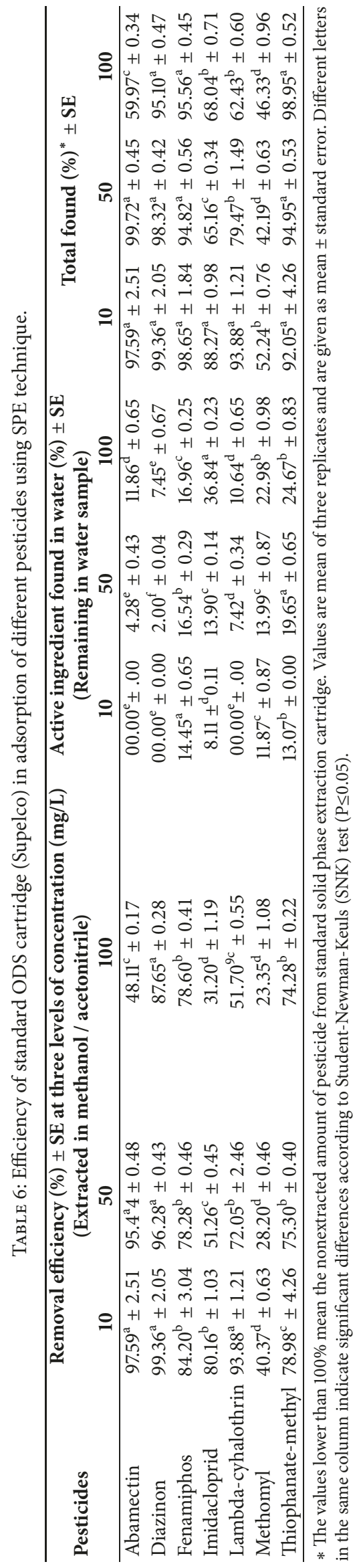


TABLE 7: Enrichment factor (EF) of Ch-Si MNPs for adsorption of different pesticides from water sample.

\begin{tabular}{|c|c|c|c|c|c|c|c|c|c|c|c|c|}
\hline \multirow{3}{*}{ Pesticides } & \multicolumn{12}{|c|}{$\mathrm{EF} \pm \mathrm{SE}$ of Ch-MO NPs at three levels of pesticide concentrations $(\mu \mathrm{g} / \mathrm{mL})$} \\
\hline & 10 & 50 & 100 & \multirow{2}{*}{\multicolumn{4}{|c|}{ Mean \pm SE Ch-ZnO NPs }} & \multirow{3}{*}{$\begin{array}{c}\text { Mean } \pm \text { SE } \\
8.71^{\mathrm{a}} \pm 0.26\end{array}$} & 10 & 50 & 100 & \multirow{3}{*}{$\begin{array}{l}\text { Mean } \pm \text { SE } \\
7.40^{\mathrm{a}} \pm 1.26\end{array}$} \\
\hline & \multicolumn{3}{|c|}{ Ch-CuO NPs } & & & & & & \multicolumn{3}{|c|}{ ODS (Supelco) } & \\
\hline Abamectin & 8.22 & 9.47 & 8.51 & $8.73^{\mathrm{a}} \pm 0.31$ & 8.28 & 9.31 & 8.54 & & 8.19 & 9.58 & 4.43 & \\
\hline Diazinon & 5.24 & 2.74 & 1.75 & $3.24^{\mathrm{b}} \pm 0.85$ & 7.04 & 6.10 & 5.93 & $6.36^{\mathrm{ab}} \pm 0.28$ & 7.42 & 7.71 & 7.17 & $7.43^{\mathrm{a}} \pm 0.13$ \\
\hline Fenamiphos & 7.56 & 7.35 & 7.24 & $7.38^{\mathrm{a}} \pm 0.08$ & 7.55 & 7.35 & 6.98 & $7.29^{\mathrm{ab}} \pm 0.14$ & 6.68 & 6.16 & 6.28 & $6.37^{\mathrm{b}} \pm 0.13$ \\
\hline Imidacloprid & 7.39 & 7.60 & 5.12 & $6.70^{\mathrm{ab}} \pm 0.65$ & 7.64 & 8.22 & 6.22 & $7.36^{\mathrm{ab}} \pm 0.49$ & 6.32 & 4.59 & 2.19 & $4.37^{\mathrm{c}} \pm 0.98$ \\
\hline Lambda-cyhalothrin & 7.87 & 10.80 & 7.31 & $8.66^{\mathrm{a}} \pm 0.89$ & 7.93 & 11.13 & 7.45 & $8.83^{\mathrm{a}} \pm 0.95$ & 7.37 & 8.18 & 4.08 & $6.54^{\mathrm{b}} \pm 1.03$ \\
\hline Methomyl & 9.34 & 5.64 & 4.31 & $6.43^{\mathrm{ab}} \pm 1.24$ & 5.02 & 3.10 & 2.47 & $3.53^{c} \pm 0.63$ & 4.89 & 2.27 & 1.58 & $2.91^{\mathrm{d}} \pm 0.83$ \\
\hline Thiophanate-methyl & 6.76 & 6.32 & 5.97 & $6.35^{\mathrm{ab}} 0.19$ & 7.23 & 4.85 & 4.81 & $5.63^{b c} \pm 0.66$ & 6.30 & 6.03 & 5.94 & $6.09^{\mathrm{b}} \pm 0.09$ \\
\hline
\end{tabular}

Values are mean of three replicates and are given as mean \pm standard error. Different letters in the same column indicate significant differences according to Student-Newman-Keuls (SNK) test $(\mathrm{P} \leq 0.05)$.

methomyl is still less compared to others. It can be observed that the standard SPE cartridge $\left(\mathrm{C}_{18}\right)$ showed a disparity in extraction efficiency and was the least cartridge compared with $\mathrm{Ch}-\mathrm{CuO} \mathrm{NPs}$ and $\mathrm{Ch}-\mathrm{ZnO} \mathrm{NPs}$ in the recovery of most tested pesticides including abamectin (recovery of 48.11-97.59\%), fenamiphos (recovery of 78.60-84.20\%), imidacloprid (recovery of 31.20-80.16\%), lambda-cyhalothrin (recovery of 51.70-93.88\%), and methomyl (recovery of 23.35$40.37 \%)$. Unfortunately, the SPE has certain limitations, primarily related to low recovery, i.e., slightly lower sensitivity, in cases where the SPE column is blocked (blocking the absorption centers by the sample's solid and organic components) [55].

The enrichment factor (EF) of the prepared and standard cartridges is shown in Table 7. EF can be defined as the concentration of the analyte in organic phase to the original concentration in the aqueous phase. The results showed that the $\mathrm{EF}$ of $\mathrm{Ch}-\mathrm{CuO} \mathrm{NPs}$ ranged from 3.24 for diazinon to 8.73 for abamectin. However, there is no significant difference among the other pesticides. The EF of $\mathrm{Ch}-\mathrm{ZnO}$ NPs ranged from 3.53 for methomyl to 8.83 for lambda-cyhalothrin. It can be noted that the EF values of the prepared cartridges were higher than the standard ODS $\left(\mathrm{C}_{18}\right)$, which had a range of 2.91-7.43.

SPE became one of the most widely used treatment methods for various samples [56, 57]. This technology has many advantages, including high enrichment factor, easy operation, high recovery, rapid phase separation, low cost, low consumption of organic solvents, and effective matrix interference [58]. In the SPE process, the synthesis of adsorbents is the fundamental issue since the type and amount of absorbance largely determine selectivity, sensitivity, and full recovery. In general, properties with large surface areas, active surface locations, and a short propagation path can provide a significant number of improvements in extraction kinetics [59]. Compared with conventional adsorbents, nanoscale metal oxides have attracted more interest from researchers in recent years, given their high surface area and rapid absorption kinetics. Several results confirmed that the ChMO NPs were high adsorbent materials and used in SPE technique for extraction and removal of different pollutants $[24,25]$. Ch-Zn was prepared and applied for removal of permethrin at optimum conditions, including adsorbent dose, agitating time, the initial concentration of pesticide, and $\mathrm{pH}$ on the adsorption [25]. The results indicated that the weight of $0.5 \mathrm{~g}$ of the bionanocomposite, at room temperature and $\mathrm{pH} \mathrm{7,} \mathrm{removed} \mathrm{99 \%} \mathrm{of} \mathrm{permethrin} \mathrm{solution}$ $(25 \mathrm{~mL}, 0.1 \mathrm{mg} \mathrm{L})$ using UV spectrophotometer at $272 \mathrm{~nm}$. Copper-coated chitosan nanocomposite $(\mathrm{Ch}-\mathrm{Cu})$ was found to have high adsorption efficiency for parathion and methyl parathion, and maximum adsorption capacity of parathion was found to be $322.60 \mathrm{mg} / \mathrm{g}$ at an optimum $\mathrm{pH}$ of 2.0 [24]. This could be attributed to the inherent alkalinity of the adsorbent. In addition, high adsorption value of malathion could be explained by acidic hydrolysis of malathion to dithiophosphate followed by complexation of copper to form $\mathrm{Cu}$ (II) dithiophosphate. Ch-AgO NPs composite beads were also optimized to remove maximum permethrin as the model pesticide, with the amount of sorbent, agitating time, initial concentration of pesticide, and $\mathrm{pH}$ parameters [2]. In optimum conditions, room temperature and $\mathrm{pH} 7$, the Ch-AgO NPs beads recovered $99 \%$ of permethrin solution $(0.10 \mathrm{mg} / \mathrm{L})$ using UV spectrophotometer compared to $50 \%$ with the pure chitosan.

3.5. Adsorption Isotherm Study. Adsorption isotherm models are important to determine the efficiency of the adsorption process. Adsorption isotherms illustrate the connection between the amount of adsorbed component per adsorbent weight and the concentration of the contaminated components in the solution. Determination of the adsorption parameters provides useful information, which can improve the adsorption efficiency of the systems. In the present study, the adsorption percentages were applied in Freundlich (1) and Langmuir (3) isotherm models as follows to predict which model is fit.

$$
\begin{aligned}
& q=K_{f} C^{1 / n} \\
& q=\frac{q_{\max } K_{l} C}{1+K_{l} C}
\end{aligned}
$$

where $\mathrm{q}$ is adsorption capacity $(\mu \mathrm{g} / \mathrm{g}) ; \mathrm{K}_{\mathrm{f}}$ is Freundlich isotherm constant $(\mu \mathrm{g} / \mathrm{g}) ; \mathrm{C}$ is concentration of the analyte 
(adsorbate) in the solution at equilibrium $(\mu \mathrm{g} / \mathrm{mL}), \mathrm{n}$ is adsorption intensity; $\mathrm{q}_{\max }$ is maximum adsorption monolayer capacity $(\mu \mathrm{g} / \mathrm{g})$; and $\mathrm{K}_{1}$ is Langmuir isotherm constant $(\mathrm{mL} / \mu \mathrm{g})$.

By analyzing the linear correlation coefficient $\left(\mathrm{R}^{2}\right)$ obtained, it is possible to identify the isotherm model that best represents the experimental data of this study [60]. From the values of $\mathrm{R}^{2}$ obtained (Table S2) for the Ch-MO NPs, it is possible to conclude that both of Langmuir and Freundlich isotherms are fit to this study with $\mathrm{R}^{2}>0.92$. When the experimental data follows the Langmuir model, this assumes that a monomolecular layer is formed when adsorption takes place without any interaction between the adsorbed molecules. However, the data follows the Freundlich isotherm, which means that the adsorption process takes place on heterogeneous surfaces and adsorption capacity is related to the concentration of the analyte at equilibrium [61]. The maximum adsorption capacity $\left(\mathrm{q}_{\max }\right)$ of Ch-MO NPs was observed for all the tested pesticides. The Ch$\mathrm{CuO}$ NPs and $\mathrm{Ch}-\mathrm{ZnO}$ NPs showed the highest adsorption capacities $\left(2.50 \times 10^{4}\right.$ and $1.00 \times 10^{5} \mu \mathrm{g} / \mathrm{g}$, respectively $)$ for thiophanate-methyl compared to $1.00 \times 10^{4} \mu \mathrm{g} / \mathrm{g}$ by using ODS $\left(\mathrm{C}_{18}\right)$. However, the insecticide methomyl showed a low $q_{\max }$ on Ch-CuO NPs and Ch-ZnO NPs $\left(2.00 \times 10^{3}, 1.00 \times\right.$ $10^{3} \mu \mathrm{g} / \mathrm{g}$, respectively) compared to $2.86 \times 10^{2}$ by using ODS $\left(\mathrm{C}_{18}\right)$.

\section{Conclusion}

Novel Ch-MO NPs, stationary phases for SPE technique, were prepared and characterized by FT-IR, SEM, TEM, XRD, and Zeta-Nano-sizer. The chromatographic retention behaviors of seven pesticides on Ch-MO NPs were investigated and compared with standard ODS ( $\mathrm{C}_{18}$ column). The factors of the $\mathrm{pH}$, temperature and agitation time were studied on the efficiency of these products in adsorption or retention of imidacloprid insecticide and the results proved that the $\mathrm{pH}$ was the most significant factor. It was reported that the ChMO NPs are able to remove the selected pesticides at the optimum condition of agitation time $25 \mathrm{~min}, \mathrm{pH} 7$, and $25^{\circ} \mathrm{C}$. $\mathrm{Ch}-\mathrm{CuO} \mathrm{NPs}$ and Ch-ZnO NPs exhibited high selectivity for the tested pesticides as solutes and the extracted amount by these products was more than the ODS in most cases at three levels of concentrations $(10,50$ and $100 \mathrm{mg} / \mathrm{L}$ in aqueous solution). The new adsorbent nanoparticles behaved as a reversed phase retention mechanism based on hydrophobic interaction as well as inclusion interactions and weak hydrophilicity for the polar pesticides such as methomyl based on partitioning and surface adsorption process. The nanoparticles will possess great prospect in chromatographic analysis especially SPE and SPME techniques. In addition, these products are newly biocompatible, environmentally friendly, and low cost to extract and clean-up pesticides from wastewater. In future, this work will be conducted on the packing of the HPLC columns with these products as new alternatives to the current stationary phases for separation of pesticide residues.

\section{Data Availability}

All data generated or analyzed during this study are included in this article. In addition, the related datasets are available from the corresponding author on reasonable request.

\section{Conflicts of Interest}

The authors confirm that they have no conflicts of interest regarding the publication of this article.

\section{Supplementary Materials}

Figure S1 shows the chemical structures of tested pesticides (abamectin, chlorpyrifos methyl, diazinon, fenamiphos, imidacloprid, lambda-cyhalothrin, methomyl, and thiophanatemethyl). Figure S2 shows the 3D-schematic diagram for preparation mechanism of Ch-MO NPs. Figure S3 shows the zeta potential distribution graph of Ch-MO NPs. Figure S4 presents the surface plot and contour plot of the adsorption (\%) of imidacloprid insecticide on Ch-CuO NPs versus temperature, $\mathrm{pH}$, and agitation time. Table $\mathrm{S} 1$ shows a summary of the methods conditions used for determination of different pesticides by HPLC system. Table $\mathrm{S} 2$ indicates the parameters of the isothermal models of Ch-MO NPs for adsorption of different pesticides. (Supplementary Materials)

\section{References}

[1] F. Ahmadi, Y. Assadi, S. M. R. M. Hosseini, and M. Rezaee, "Determination of organophosphorus pesticides in water samples by single drop microextraction and gas chromatographyflame photometric detector," Journal of Chromatography A, vol. 1101, no. 1-2, pp. 307-312, 2006.

[2] B. Rahmanifar and S. Moradi Dehaghi, "Removal of organochlorine pesticides by chitosan loaded with silver oxide nanoparticles from water," Clean Technologies and Environmental Policy, vol. 16, no. 8, pp. 1781-1786, 2014.

[3] K. L. Howdeshell, A. K. Hotchkiss, and L. E. Gray, "Cumulative effects of antiandrogenic chemical mixtures and their relevance to human health risk assessment," International Journal of Hygiene and Environmental Health, vol. 220, no. 2, pp. 179-188, 2017.

[4] K.-H. Kim, E. Kabir, and S. A. Jahan, "Exposure to pesticides and the associated human health effects," Science of the Total Environment, vol. 575, pp. 525-535, 2017.

[5] A. M. Cimino, A. L. Boyles, K. A. Thayer, and M. J. Perry, "Effects of neonicotinoid pesticide exposure on human health: A systematic review," Environmental Health Perspectives, vol. 125, no. 2, pp. 155-162, 2017.

[6] K. Yoshizuka, Z. Lou, and K. Inoue, "Silver-complexed chitosan microparticles for pesticide removal," Reactive and Functional Polymers, vol. 44, no. 1, pp. 47-54, 2000.

[7] S. D. Zaugg, M. W. Sandstrom, S. G. Smith, and K. M. Fehlberg, "Methods of analysis by the US Geological Survey National Water Quality Laboratory; determination of pesticides in water by C-18 solid-phase extraction and capillary-column gas chromatography/mass spectrometry with selected-ion monitoring," US Geological Survey: Open-File Reports Section/ESIC, 1995. 
[8] D. A. J. Murray, "Rapid micro extraction procedure for analyses of trace amounts of organic compounds in water by gas choromatography and comparisons with macro extraction methods," Journal of Chromatography A, vol. 177, no. 1, pp. 135-140, 1979.

[9] I. Liška, J. Krupčíik, and P. A. Leclercq, "The use of solid sorbents for direct accumulation of organic compounds from water matrices-a review of solid-phase extraction techniques," Journal of High Resolution Chromatography, vol. 12, no. 9, pp. 577-590, 1989.

[10] M. T. Muldoon and L. H. Stanker, "Molecularly imprinted solid phase extraction of atrazine from beef liver extracts," Analytical Chemistry, vol. 69, no. 5, pp. 803-808, 1997.

[11] S. M. Yousefi, F. Shemirani, and S. A. Ghorbanian, "Deep eutectic solvent magnetic bucky gels in developing dispersive solid phase extraction: Application for ultra trace analysis of organochlorine pesticides by GC-micro ECD using a largevolume injection technique," Talanta, vol. 168, pp. 73-81, 2017.

[12] T. A. Albanis, D. G. Hela, T. M. Sakellarides, and I. K. Konstantinou, "Monitoring of pesticide residues and their metabolites in surface and underground waters of Imathia (N. Greece) by means of solid-phase extraction disks and gas chromatography," Journal of Chromatography A, vol. 823, no. 1-2, pp. 59-71, 1998.

[13] T. F. Jenkins, P. H. Miyares, K. F. Myers, E. F. McCormick, and A. B. Strong, "Comparison of solid phase extraction with saltingout solvent extraction for preconcentration of nitroaromatic and nitramine explosives from water," Analytica Chimica Acta, vol. 289, no. 1, pp. 69-78, 1994.

[14] G.-M. Momplaisir, C. G. Rosal, E. M. Heithmar et al., "Development of a solid phase extraction method for agricultural pesticides in large-volume water samples," Talanta, vol. 81, no. 4-5, pp. 1380-1386, 2010.

[15] Y. S. Al-Degs, M. A. Al-Ghouti, and A. H. El-Sheikh, "Simultaneous determination of pesticides at trace levels in water using multiwalled carbon nanotubes as solid-phase extractant and multivariate calibration," Journal of Hazardous Materials, vol. 169, no. 1-3, pp. 128-135, 2009.

[16] L. Vidal, M.-L. Riekkola, and A. Canals, "Ionic liquid-modified materials for solid-phase extraction and separation: a review," Analytica Chimica Acta, vol. 715, pp. 19-41, 2012.

[17] L. Costa dos Reis, L. Vidal, and A. Canals, "Graphene oxide/ $\mathrm{Fe} 3 \mathrm{O} 4$ as sorbent for magnetic solid-phase extraction coupled with liquid chromatography to determine 2,4,6-trinitrotoluene in water samples," Analytical and Bioanalytical Chemistry, vol. 409, no. 10, pp. 2665-2674, 2017.

[18] A. Zwir-Ferenc and M. Biziuk, "Solid phase extraction technique - Trends, opportunities and applications," Polish Journal of Environmental Studies, vol. 15, no. 5, pp. 677-690, 2006.

[19] J. Pawliszyn, Solid phase microextraction: theory and practice, John Wiley Sons, 1997.

[20] M. E. Badawy, E. I. Rabea, N. E. Taktak, and M. A. El Nouby, "Production and Properties of Different Molecular Weights of Chitosan from Marine Shrimp Shells," Journal of Chitin and Chitosan Science, vol. 4, no. 1, pp. 46-54, 2016.

[21] E. I. Rabea, M. E.-T. Badawy, C. V. Stevens, G. Smagghe, and W. Steurbaut, "Chitosan as antimicrobial agent: applications and mode of action," Biomacromolecules, vol. 4, no. 6, pp. 1457-1465, 2003.

[22] A. Domard and M. Domard, "Chitosan: structure-properties relationship and biomedical applications," Polymeric Biomaterials, vol. 2, pp. 187-212, 2001.
[23] M. Masuelli and D. Renard, Advances in Physicochemical Properties of Biopolymers (Part 2), BENTHAM SCIENCE PUBLISHERS, 2017.

[24] M. Jaiswal, D. Chauhan, and N. Sankararamakrishnan, "Copper chitosan nanocomposite: Synthesis, characterization, and application in removal of organophosphorous pesticide from agricultural runoff," Environmental Science and Pollution Research, vol. 19, no. 6, pp. 2055-2062, 2012.

[25] S. Moradi Dehaghi, B. Rahmanifar, A. M. Moradi, and P. A. Azar, "Removal of permethrin pesticide from water by chitosanzinc oxide nanoparticles composite as an adsorbent," Journal of Saudi Chemical Society, vol. 18, no. 4, pp. 348-355, 2014.

[26] S. Sarkar, E. Guibal, F. Quignard, and A. K. SenGupta, "Polymersupported metals and metal oxide nanoparticles: synthesis, characterization, and applications," Journal of Nanoparticle Research, vol. 14, no. 2, article 715, 2012.

[27] M. E. I. Badawy, N. E. M. Taktak, O. M. Awad, S. A. Elfiki, and N. E. A. El-Ela, "Preparation and Characterization of Biopolymers Chitosan/Alginate/Gelatin Gel Spheres Crosslinked by Glutaraldehyde," Journal of Macromolecular Science, Part B Physics, vol. 56, no. 6, pp. 359-372, 2017.

[28] C. Tual, E. Espuche, M. Escoubes, and A. Domard, "Transport properties of chitosan membranes: Influence of crosslinking," Journal of Polymer Science Part B: Polymer Physics, vol. 38, no. 11, pp. 1521-1529, 2000.

[29] W.-W. Xiong, W.-F. Wang, L. Zhao, Q. Song, and L.-M. Yuan, "Chiral separation of (R,S)-2-phenyl-1-propanol through glutaraldehyde-crosslinked chitosan membranes," Journal of Membrane Science, vol. 328, no. 1-2, pp. 268-272, 2009.

[30] M. Gabriel Paulraj, S. Ignacimuthu, M. R. Gandhi et al., "Comparative studies of tripolyphosphate and glutaraldehyde crosslinked chitosan-botanical pesticide nanoparticles and their agricultural applications," International Journal of Biological Macromolecules, vol. 104, pp. 1813-1819, 2017.

[31] W. Tong, C. Gao, and H. Möhwald, "Manipulating the properties of polyelectrolyte microcapsules by glutaraldehyde crosslinking," Chemistry of Materials, vol. 17, no. 18, pp. 4610-4616, 2005.

[32] S. Honary and F. Zahir, "Effect of zeta potential on the properties of nano-drug delivery systems-a review (part 1)," Tropical Journal of Pharmaceutical Research, vol. 12, no. 2, pp. 255-264, 2013.

[33] J. L. D. O. Arias, C. Rombaldi, S. S. Caldas, and E. G. Primel, "Alternative sorbents for the dispersive solid-phase extraction step in quick, easy, cheap, effective, rugged and safe method for extraction of pesticides from rice paddy soils with determination by liquid chromatography tandem mass spectrometry," Journal of Chromatography A, vol. 1360, pp. 66-75, 2014.

[34] M. E. Badawy, A. E. Marei, and M. A. El-Nouby, "Preparation and characterization of chitosan-siloxane magnetic nanoparticles for the extraction of pesticides from water and determination by HPLC, Separation Science Plus, vol. 1, no. 7, pp. 506-519, 2018.

[35] US Department of Health and Human Services (FDA), Analytical Procedures And Methods Validation Chemistry, Manufacturing, And Controls Documentation, vol. 65, 2000.

[36] A. Teasdale, D. Elder, and R. W. Nims, ICH Quality Guidelines, John Wiley \& Sons, Inc., Hoboken, NJ, USA, 2017.

[37] A. Shrifian-Esfahni, M. T. Salehi, M. Nasr-Esfahni, and E. Ekramian, "Chitosan-modified superparamgnetic iron oxide nanoparticles: Design, fabrication, characterization and antibacterial activity," Chemik, vol. 69, no. 1, pp. 19-32, 2015. 
[38] A. M. Muthukrishnan, "Green synthesis of copper-chitosan nanoparticles and study of its antibacterial activity," Journal of Nanomedicine \& Nanotechnology, vol. 6, no. 1, 2015.

[39] M. Gouda and A. Hebeish, "Preparation and evaluation of $\mathrm{CuO} /$ chitosan nanocomposite for antibacterial finishing cotton fabric," Journal of Industrial Textiles, vol. 39, no. 3, pp. 203-214, 2010.

[40] K. L. Haas and K. J. Franz, "Application of metal coordination chemistry to explore and manipulate cell biology," Chemical Reviews, vol. 109, no. 10, pp. 4921-4960, 2009.

[41] F. S. Pereira, S. Lanfredi, E. R. P. González, D. L. da Silva Agostini, H. M. Gomes, and R. dos Santos Medeiros, "Thermal and morphological study of chitosan metal complexes," Journal of Thermal Analysis and Calorimetry, vol. 129, no. 1, pp. 291-301, 2017.

[42] M. S. Usman, N. A. Ibrahim, K. Shameli, N. Zainuddin, and W. M. Z. W. Yunus, "Copper nanoparticles mediated by chitosan: synthesis and characterization via chemical methods," Molecules, vol. 17, no. 12, pp. 14928-14936, 2012.

[43] P. Senthil Kumar, M. Selvakumar, S. Ganesh Babu, S. Induja, and S. Karuthapandian, "CuO/ZnO nanorods: An affordable efficient $\mathrm{p}-\mathrm{n}$ heterojunction and morphology dependent photocatalytic activity against organic contaminants," Journal of Alloys and Compounds, vol. 701, pp. 562-573, 2017.

[44] L.-H. Li, J.-C. Deng, H.-R. Deng, Z.-L. Liu, and L. Xin, "Synthesis and characterization of chitosan/ZnO nanoparticle composite membranes," Carbohydrate Research, vol. 345, no. 8, pp. 994-998, 2010.

[45] S. Patil, A. Sandberg, E. Heckert, W. Self, and S. Seal, "Protein adsorption and cellular uptake of cerium oxide nanoparticles as a function of zeta potential," Biomaterials, vol. 28, no. 31, pp. 4600-4607, 2007.

[46] A. Regiel-Futyra, M. Kus-Liśkiewicz, S. Wojtyła, G. Stochel, and W. Macyk, "The quenching effect of chitosan crosslinking on $\mathrm{ZnO}$ nanoparticles photocatalytic activity," RSC Advances, vol. 5, no. 97, pp. 80089-80097, 2015.

[47] Y. Gao, K.-H. Lee, M. Oshima, and S. Motomizu, "Adsorption behavior of metal ions on cross-linked chitosan and the determination of oxoanions after pretreatment with a chitosan column," Analytical Sciences, vol. 16, no. 12, pp. 1303-1308, 2000.

[48] I. A. Udoetok, R. M. Dimmick, L. D. Wilson, and J. V. Headley, "Adsorption properties of cross-linked cellulose-epichlorohydrin polymers in aqueous solution," Carbohydrate Polymers, vol. 136, pp. 329-340, 2016.

[49] A. Bagabas, A. Alshammari, M. F. A. Aboud, and H. Kosslick, "Room-temperature synthesis of zinc oxide nanoparticles in different media and their application in cyanide photodegradation," Nanoscale Research Letters, vol. 8, no. 1, pp. 1-10, 2013.

[50] S. Basumallick and S. Santra, "Chitosan coated copper-oxide nano particles: A novel electro-catalyst for $\mathrm{CO}_{2}$ reduction," RSC Advances, vol. 4, no. 109, pp. 63685-63690, 2014.

[51] Z. Pápai and T. L. Pap, "Determination of chromatographic peak parameters by non-linear curve fitting using statistical moments," Analyst, vol. 127, no. 4, pp. 494-498, 2002.

[52] G. I. K. Marei, E. I. Rabea, and M. E. Badawy, "Preparation and Characterizations of Chitosan/Citral Nanoemulsions and their Antimicrobial Activity," Applied Food Biotechnology, vol. 5, pp. 69-78, 2018.

[53] J. Liu, X. Lü, J. Xie, Y. Chu, C. Sun, and Q. Wang, "Adsorption of lambda-cyhalothrin and cypermethrin on two typical Chinese soils as affected by copper," Environmental Science and Pollution Research, vol. 16, no. 4, pp. 414-422, 2009.
[54] R. I. Krieger, P. Brutsche-Keiper, H. R. Crosby, and A. D. Krieger, "Reduction of pesticide residues of fruit using water only or plus Fit ${ }^{\mathrm{TM}}$ Fruit and Vegetable Wash," Bulletin of Environmental Contamination and Toxicology, vol. 70, no. 2, pp. 213-218, 2003.

[55] R. Đurovic and T. Đordevic, Modern extraction techniques for pesticide residues determination in plant and soil samples Pesticides in the Modern World-Trends in Pesticides Analysis, InTech, 2011.

[56] Ł. Rajski, A. Lozano, A. Uclés, C. Ferrer, and A. R. FernándezAlba, "Determination of pesticide residues in high oil vegetal commodities by using various multi-residue methods and clean-ups followed by liquid chromatography tandem mass spectrometry," Journal of Chromatography A, vol. 1304, pp. 109120, 2013.

[57] D. Molins-Delgado, D. García-Sillero, M. S. Díaz-Cruz, and D. Barceló, "On-line solid phase extraction-liquid chromatography-tandem mass spectrometry for insect repellent residue analysis in surface waters using atmospheric pressure photoionization," Journal of Chromatography A, vol. 1544, pp. 33-40, 2018.

[58] Z. Li, J. Li, Y. Wang, and Y. Wei, "Synthesis and application of surface-imprinted activated carbon sorbent for solid-phase extraction and determination of copper (II)," Spectrochimica Acta Part A: Molecular and Biomolecular Spectroscopy, vol. 117, pp. 422-427, 2014.

[59] R. Khorasani, K. Dindarloo Inaloo, M. Heidari, M. Behbahani, and O. Rahmanian, "Application of solvent-assisted dispersive solid phase extraction combined with flame atomic absorption spectroscopy for the determination of trace amounts of Cadmium," Hormozgan Medical Journal, vol. 20, no. 6, pp. 383-392, 2017.

[60] P. M. Silva, J. E. Francisco, J. C. Cajé, R. J. Cassella, and W. F. Pacheco, "A batch and fixed bed column study for fluorescein removal using chitosan modified by epichlorohydrin," Journal of Environmental Science and Health, Part A: Toxic/Hazardous Substances and Environmental Engineering, vol. 53, no. 1, pp. 5564, 2017.

[61] F. Naseeruteen, N. S. A. Hamid, F. B. M. Suah, W. S. W. Ngah, and F. S. Mehamod, "Adsorption of malachite green from aqueous solution by using novel chitosan ionic liquid beads," International Journal of Biological Macromolecules, vol. 107, pp. 1270-1277, 2018. 

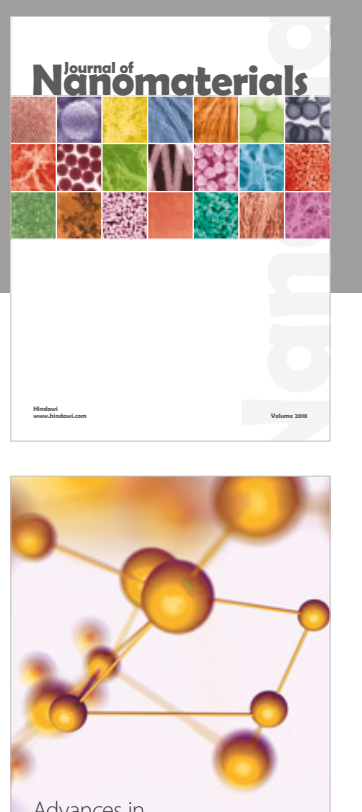

Physical Chemistry
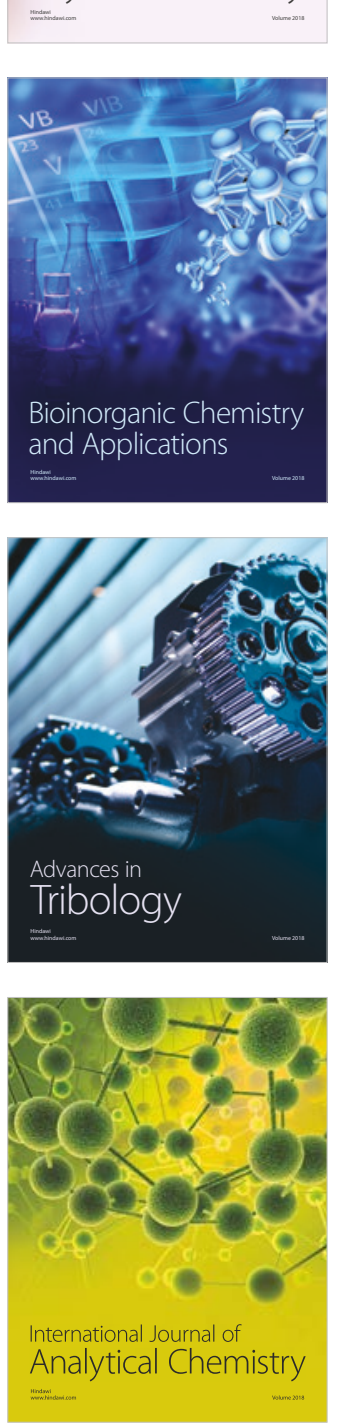

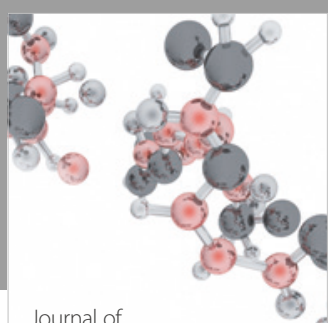

Analytical Methods

in Chemistry

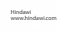

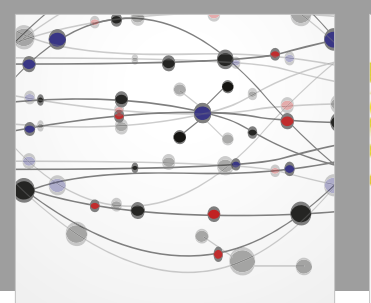

The Scientific World Journal

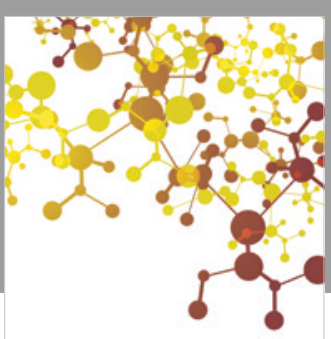

Journal of

Applied Chemistry
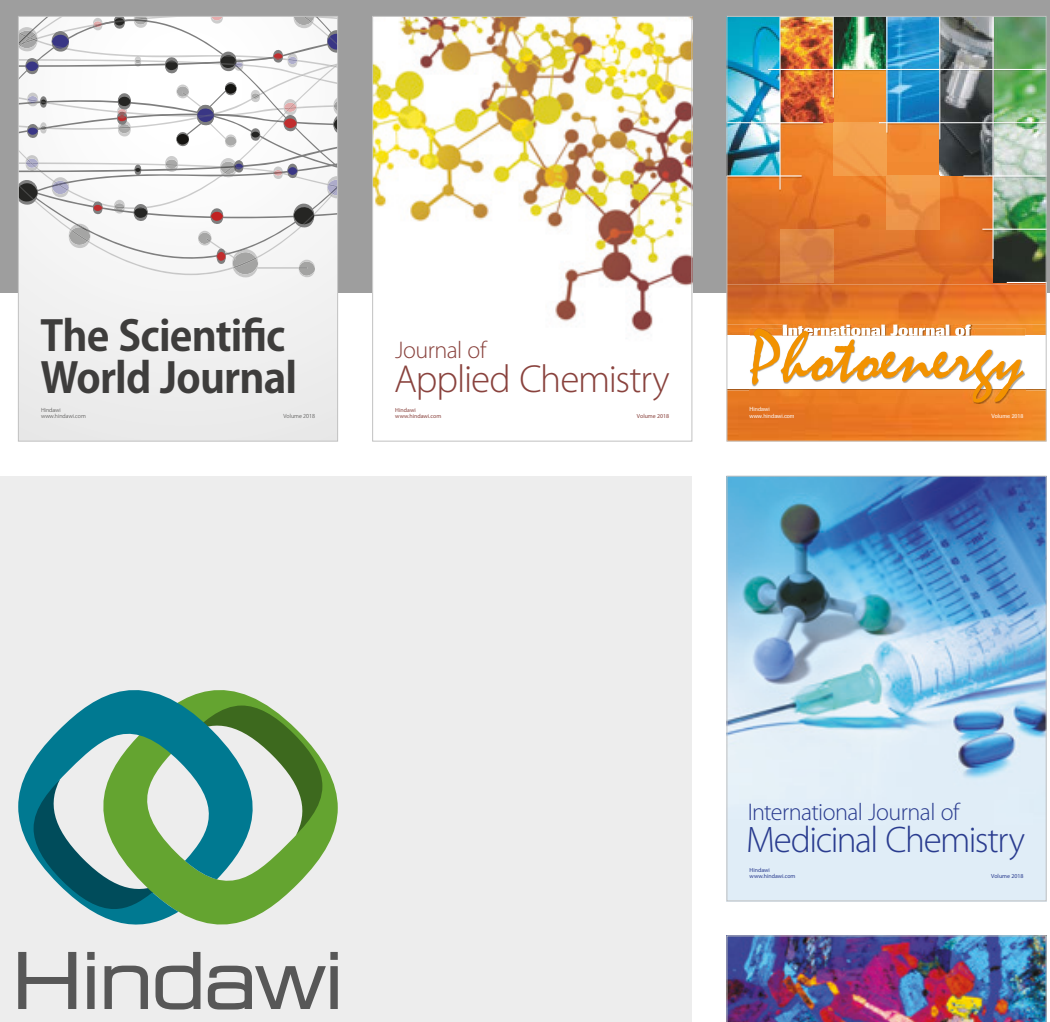

Submit your manuscripts at

www.hindawi.com
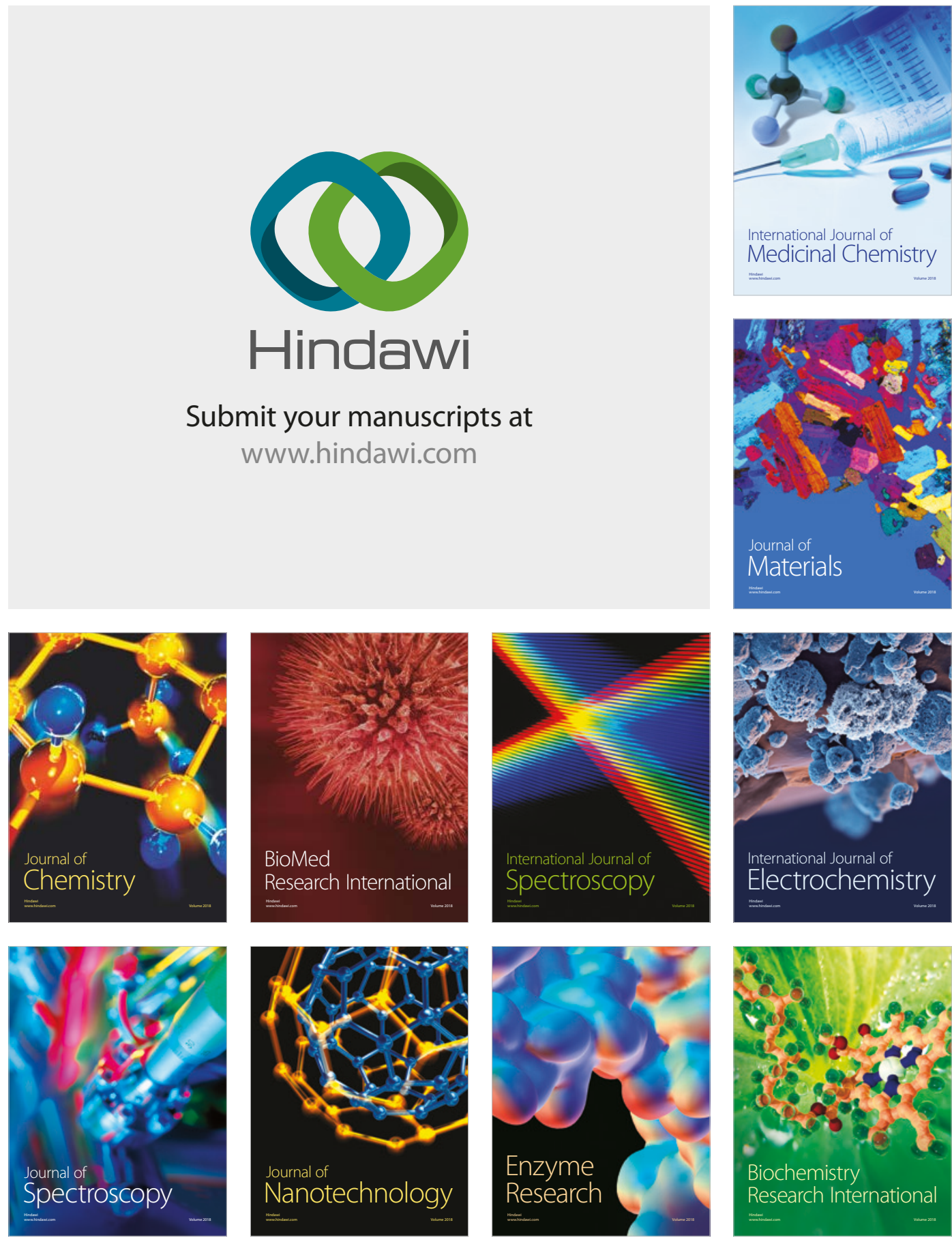
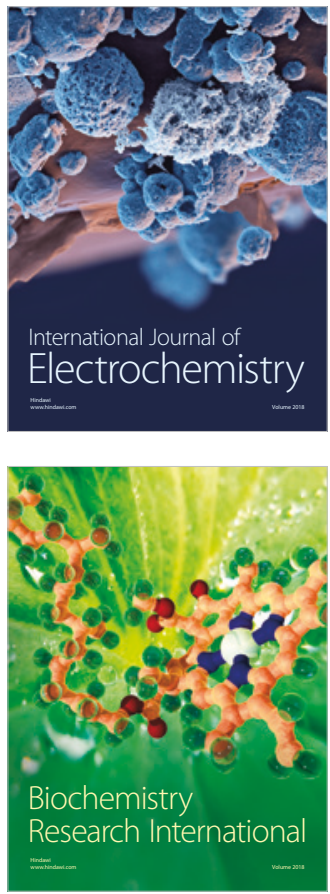